\title{
STEP DOUBLE BARRIER OPTIONS
}

(published in Journal of Derivatives, Fall 2010)

Author : Tristan Guillaume

Mailing address : Université de Cergy-Pontoise, Laboratoire Thema, 33 boulevard du port, F-95011

Cergy-Pontoise Cedex, France

E-mail address : tristan.guillaume@u-cergy.fr

Telephone number : + 33612224588

Fax number : + 33134256233 


\begin{abstract}
Double barrier options have been traded for a long time in the markets and they are embedded in a variety of popular structured products. However, in their standard form, they lack flexibility inasmuch as they feature a constant barrier level during the entire option life. Step double barrier options overcome this limitation by allowing investors to set the knock-out or knock-in levels they want at the time of their choosing rather than by imposing an arbitrary mathematical form upon the time-varying double barrier. Although step double barrier options are actively traded, no analytical formula is known for their valuation and hedging. In this paper, not only regular step double barrier options are analytically valued, but also more exotic contracts combining periods with and without active barriers as well as step double barrier options written on several assets. Financial properties of these instruments are discussed in comparison with other existing contracts.
\end{abstract}




\section{INTRODUCTION}

There is one type of exotic double barrier option that is popular in the OTC markets and that admits no known analytical valuation formula. It is usually referred to as a "step double barrier option", or as a "multi-barrier double touch / no touch" or, more briefly, as a "tunnel" (which is often characterized as "expanding" or "shrinking"); some practioners have also called it a "hot-dog option". Behind these different names, the common feature of these instruments is that the double barrier evolves in time as a piecewise constant function. It seems therefore advisable to refer to them as step double barrier options, because this expression points precisely to the fact that the double barrier is a step function of time. These contracts appeal to investors because they are more flexible than standard double barrier options. They are embedded in a variety of popular structured products, such as range notes and loans (also known as tunnel notes and loans), tower notes and loans (also called "wedding cakes" or "onion options"), or range forward contracts. Standard range notes are short-term or medium-term index-linked notes, usually fully capital guaranteed, whereby the investor receives a minimum coupon below the market if the underlying index leaves a predefined range at least once between trade time and expiration time, and a coupon above the market rate if the underlying index remains inside the predefined range at all times. In other words, the investor waives part of his or her market coupon to go long a double no-touch. This is particularly relevant at times when the implied volatility is high compared to the historical movements of the underlying index. One can also design the same structure as a loan, where the client is charged a best case interest rate below market if no knock-out condition is triggered until expiry. Similarly, range forward contracts entitle their holders to buy or sell an agreed amount of a certain asset on a given date at a preferential rate, more favourable than the outright forward rate, if a prespecified knock-out or knock-in range condition is met. The tower note takes the idea of the tunnel note and develops it further by allowing the investor to build up higher and higher coupons like in a tower depending on which range the underlying asset remains within. This involves waiving part of the market coupon to go long a portfolio of nested double-notouch contracts. For more material on this and other related products, the reader is referred to Wystup [2006].

All these range-type contracts are valuable financial innovations, however, in their standard form, they expose investors to the notorious danger of "sudden death", meaning that the entire claim to an enhanced yield is lost at the first passage time to a knock-out barrier. There are several ways to manage this risk. One of them, which has grown increasingly popular, consists in structuring rangetype contracts by using step double barrier options instead of standard double barrier options. The risk of knocking-out or not knocking-in can then be adjusted according to the investors' market anticipations or to their level of risk-aversion. For instance, risk-averse investors will typically specify that the permitted ranges of fluctuation widen over time (a specification often referred to as an "expanding tunnel"), making the deactivation of their contingent claim less and less likely. Based on 
this approach, clients can be further protected by making the trigger mechanism gradual, i.e. by removing only a fraction of the option payoff once one of the exit points is crossed.

From a financial engineering point of view, these valuable extensions to the initial first generation contracts rely on the use of double barrier options featuring non-constant double barriers to structure the notes. Hitherto, the only special case among such options that has been analytically priced is one in which the double barrier is an exponential function of time (Kunitomo and Ikeda [1992]). Compared to such an instrument, the advantages of step double barrier options are manifold, as they offer transparency, simplicity and flexibility. First, investors are not faced with the problem of being insecure about the location of the barrier at any instant during the option life, since the barrier is piecewise constant. More importantly, they are free to set exactly the knock-out or knock-in levels they want at the time of their choosing instead of being imposed upon an arbitrary mathematical form. For instance, with exponentially growing or decreasing barriers, one cannot define contracts whereby the double barrier evolves in time in a non-monotonic way, whereas this is not an issue when the double barrier is a step function of time. It must be recalled that the main motivation for defining double barriers as exponential functions of time is technical : it makes calculations easy. Clearly, from a market point of view, it is better to let investors set their own contract specifications the way they want rather than restrict the form of the contract on modelling grounds. It is therefore no wonder that exponential double barrier options are scarcely traded, unlike step double barrier options, which make up the building block for the more flexible second generation of range-type structured products that were previously described.

The valuation and hedging of step double barrier options is thus an important question for market practitioners. There are non-trivial issues in numerical integration that render analytical formulae pointless when there are many steps in the double barrier. However, when the number of steps is restricted to two, closed form formulae can be obtained that yield option prices and hedging parameters as accurately and efficiently as possible. Not only these two-step double barrier options are intrinsically worth studying, but the formulae obtained for their valuation also allow to gain insight into the properties of more general step barrier options. Moreover, exotic instruments such as partialtime and multi-asset or rainbow two-step double barrier options can be valued in closed form too. Finally, these formulae form the basis for an efficient semi-analytical pricing method for general step double barrier options with any number of steps.

In this paper, step double barrier options are introduced, discussed from a financial point of view and mathematically valued, starting with regular two-step double barrier options (Section 1), then moving on to partial-time two-step double barrier options (Section 2), followed by rainbow two-step double barrier options (Section 3). Formulae are given in Appendix 1, while Appendix 2 provides an algorithm for efficiently valuing step double barrier options with an arbitrary number of steps. All the exhibits mentioned in the article appear following Appendix 2. 


\section{REGULAR STEP DOUBLE BARRIER OPTIONS}

Let $\left\{\mathrm{t}_{0}=0 ; \mathrm{t}_{1} ; \ldots ; \mathrm{t}_{\mathrm{n}-1} ; \mathrm{t}_{\mathrm{n}}=\mathrm{T}\right\}$ be a subdivision of the option lifetime $[0 ; \mathrm{T}]$. In general, an $\mathrm{n}$ - step double barrier option is an option in which the double barrier is a piecewise constant function over the intervals $\left[\mathrm{t}_{\mathrm{i}}, \mathrm{t}_{\mathrm{i}+1}\right], \mathrm{i} \in\{0 ; 1 ; \ldots ; \mathrm{n}-1\}$. In other words, each time interval $\left[\mathrm{t}_{\mathrm{i}}, \mathrm{t}_{\mathrm{i}+1}\right]$ is associated with a constant double barrier $\left[\mathrm{D}_{\mathrm{i}} ; \mathrm{U}_{\mathrm{i}}\right]$, where $\mathrm{D}_{\mathrm{i}}$ is the lower part and $\mathrm{U}_{\mathrm{i}}$ is the upper part. Each pair $\left(\left[\mathrm{t}_{\mathrm{i}}, \mathrm{t}_{\mathrm{i}+1}\right],\left[\mathrm{D}_{\mathrm{i}} ; \mathrm{U}_{\mathrm{i}}\right]\right)$ is prespecified in the option contract.

A standard $n$ - step double knock-out call or put is a contract that has the same payoff as a standard call or put at expiry provided that the underlying asset price has always stayed in the ranges $\left[\mathrm{D}_{\mathrm{i}} ; \mathrm{U}_{\mathrm{i}}\right]$ in every time interval $\left[t_{i}, t_{i+1}\right]$; otherwise, it expires worthless. There are several ways to accommodate this standard payoff rule in order to make it less stringent. One of them is to introduce a rebate provision in the contract in the event of knocking-out. Another one, mentioned in the introduction, consists in defining a gradual knock-out pattern whereby a decreasing fraction of the payoff is left to the option holder as more and more steps $\left[\mathrm{D}_{\mathrm{i}} ; \mathrm{U}_{\mathrm{i}}\right]$ of the double barrier are crossed. A standard $n-$ step double knock-in call or put is a contract that has the same payoff as a standard call or put at expiry provided that at least one of the upper steps or one of the lower steps has been hit before the option maturity. A gradual knock-in pattern can be agreed upon to make the acquisition of a standard call or put less easy.

Step double barrier options are suited to investors who wish to set different levels of the double barrier at chosen moments during the option lifetime. This is particularly relevant when it is known at the contract inception that certain events that will occur during the option lifetime are likely to affect the risk of knocking-out (or the chances of knocking-in). When that risk is supposed to increase, you might want to set the knock-out barriers further away from the spot. Similarly, if you anticipate the volatility of the underlying asset to rise at some point, then you could widen the knock-in range at that moment. All these possibilities are not allowed by standard double barrier options.

Let us now focus on a few examples for a better understanding of the properties of these instruments. In the following analysis, two-step double barrier options are considered. They are denoted as TSDKO (standing for Two-Step Double Knock-Out) options when they are of knock-out type and as TSDKI (standing for Two-Step Double Knock-In) options when they are of knock-in type. Similarly, standard double barrier options are denoted as either DKO or DKI options. All mentioned TSDKO and TSDKI prices are obtained by using Proposition 1 in Appendix 1 . When $\mathrm{D}_{1}=\mathrm{D}_{2}$ and $\mathrm{U}_{1}=\mathrm{U}_{2}$, Proposition 1 yields the value of a standard double barrier option. A double barrier $\left[\mathrm{D}_{2} ; \mathrm{U}_{2}\right]$ is referred to as "wider" than another double barrier $\left[\mathrm{D}_{1} ; \mathrm{U}_{1}\right]$ if $\mathrm{D}_{2} \leq \mathrm{D}_{1}$ and $\mathrm{U}_{2} \geq \mathrm{U}_{1}$. Similarly, $\left[\mathrm{D}_{2} ; \mathrm{U}_{2}\right]$ is 
"narrower" than $\left[\mathrm{D}_{1} ; \mathrm{U}_{1}\right]$ if $\mathrm{D}_{2} \geq \mathrm{D}_{1}$ and $\mathrm{U}_{2} \leq \mathrm{U}_{1}$. Notice, however, that Proposition 1 is also valid when both the lower and the upper parts of the barrier increase or decrease, i.e. when $D_{2} \geq D_{1}$ and $\mathrm{U}_{2} \geq \mathrm{U}_{1}$ or when $\mathrm{D}_{2} \leq \mathrm{D}_{1}$ and $\mathrm{U}_{2} \leq \mathrm{U}_{1}$. This remark applies to all the other formulae that will subsequently appear in this paper. Also, the extension of the valuation method to general $n-$ step double barrier options is dealt with in Appendix 2.

If your need for protection diminishes during a certain period, for example because you anticipate the volatility of the underlying asset to decrease, then you had better set a narrower knock-out double barrier at that particular time in order to reduce your hedging costs. Exhibit 2 shows the effect of only slightly narrowing the double barrier during the second half of the life of a six-month expiry double knock-out put for various levels of strike and volatility, compared with the costs involved by a constant double barrier up until expiry in Exhibit 1 . The average price reduction entailed by the TSDKO put, relative to a DKO put, is approximately $45 \%$ when the option is out-of-the-money, $27 \%$ when the option is at-the-money and $19 \%$ when the option is in-the-money.

Conversely, if at some point in time the risk of knocking-out is likely to increase, you might want to widen the double barrier so that you can be better protected at the right time. Exhibit 4 shows how a moderate widening of the double barrier during the second half of the option life results in a substantial reduction in the danger of knocking-out before expiry. Averaging over the different levels of volatility, that risk is divided by 3.5 when maturity is six months and by 1.75 when maturity is one year. The average reduction in the probability of knocking-out is thus very large. The major part of it, though, is attained when volatility is low, that is at a level in which risk is low anyway, whether you hold a DKO option or a TSDKO option. When volatility stands at an "intermediate" level (30\%), the risk reduction entailed by TSDKO options remains definitely significant, since the probability of knocking-out is still divided by 1.88 when expiry is six months and by 1.39 when expiry is one year.

Looking back on the two previous examples, it is clear that, in a market without step double barrier options, you will have no choice but to hold a double barrier option either with the wider double barrier or with the narrower double barrier during the entire option life. In the first case, you will be over-protected and your hedging costs will be too high relative to your needs; in the second case, you will be under-protected and your risk exposure will be too high. The combination of cost saving and protection thus cannot be optimal in a market without step double barrier options.

To understand the specificity of a TSDKO option, it is important to analyse the sentivity of the option premium to a change in the level of the double barrier at time $t_{1}$. Regardless of the volatility of the underlying asset and of the moneyness of the contract, this sensitivity is heavily dependent on the location of $t_{1}$ and on the level of the first double barrier. If both $\mathrm{D}_{1}$ and $\mathrm{U}_{1}$ are very close to the spot, the sentivity under consideration will be low, because, whatever widening of the double barrier occurs at time $t_{1}$, the chances that the option has remained alive on $t_{1}$ are slim. Take, for example, an at-the- 
money TSDKO put with $\mathrm{S}(0)=100, \mathrm{U}_{1}=105, \mathrm{D}_{1}=95, \mathrm{U}_{2}=150, \mathrm{D}_{2}=50, \sigma=25 \%, \mathrm{r}=3 \%, \mathrm{t}_{1}=$ 3 months, $t_{2}=6$ months : the value of this contingent claim is almost zero, and there is no significant difference between a DKO and a TSDKO option in this case. The only exception to the latter rule is when $t_{1}$ is very early in the option life : if you restrict the time interval $\left[t_{0} ; t_{1}\right]$ in the previous example to two weeks, the option value jumps to 2.16. As $D_{1}$ and $U_{1}$ are set relatively close to the spot but not too close, the dependency of the option value on the choice of $t_{1}$ increases, all the more so as the second double barrier widens relative to the first one : the value of the same option as before, with $t_{1}=3$ months, rises to 4.733 when $U_{1}$ is set at 120 and $D_{1}$ is set at 80 , whereas this option would be worth 2.14 without a change in the double barrier at time $t_{1}$ (i.e., if this option were a DKO one with a unique $[80 ; 120]$ range); and the gap between these two prices would increase sharply for a longer maturity or a greater volatility parameter. Now if $D_{1}$ and $U_{1}$ are far from the spot and the second double barrier is much narrower than the first one, the sensitivity of the option value to the change in the double barrier will be high, even if $t_{1}$ is close to expiry; take $U_{1}=150, D_{1}=50, U_{2}=$ $110, \mathrm{D}_{2}=90, \mathrm{t}_{1}=0.45, \mathrm{t}_{2}=0.5$, and your option value falls as low as 0.515 , although the double barrier is quite wide for almost the entire option life. In the limit, if you set $U_{2}$ and $D_{2}$ arbitrarily close to the spot, your option value will always tend to zero even if $t_{1}$ is as close to $t_{2}$ as you want.

It may seem natural to think that, when one range is wider than the other, then the longer the time interval in which the wider range is monitored, the more valuable the knock-out option becomes. However, the order in which ranges are monitored does matter. Because the probability of knockingout tends to decrease as the double barrier widens over time and tends to increase as the double barrier shrinks, TSDKO options are often more valuable when the wider double barrier is monitored subsequent to the narrower double barrier, all other things being equal. A counter-intuitive implication of the latter observation is that there are many TSDKO options that will be more valuable than other similar TSDKO options in which the wider double barrier is monitored longer but prior to the narrower double barrier.

Another important question in terms of pricing and risk management is the sensitivity of the TSDKO option to the volatility of the underlying asset. It is well known that, unlike vanilla options, knock-out barrier options are not monotonic functions of volatility. Indeed, an increase in volatility has two opposite effects : on the one hand, it raises the chances of expiring in-the-money; on the other hand, the odds of being knocked-out before expiry rise too. Whichever of these two effects prevails depends on the moneyness of the contract, on the double barrier level and on the option maturity. Broadly speaking, if the option is moderately out-of-the-money, an increase in the volatility of the underlying asset will exert a strongly positive effect on the option value, provided that neither part of the double barrier stands too dangerously close to the spot. That positive effect, however, will decrease in the 
option maturity, even if the barrier is relatively distant from the spot. Most long maturity double knock-out options, indeed, have very little value compared with long maturity vanilla options. When the option is heavily out-of-the-money, an increase in the volatility of the underlying asset will exert a strongly negative effect on the option value, because the spot is too far from the strike for the probability of expiring in-the-money to be positively affected in a significant manner, while the adverse effect on the probability of knocking-out manifests itself (the risk of hitting the upper barrier for a put and the risk of hitting the lower barrier for a call). It is thus important to determine the spot range in which the sensitivity of the option value to an increase in volatility changes sign, which is easily done with an analytical formula such as the one given in Proposition 1 in Appendix 1.

\section{PARTIAL-TIME STEP DOUBLE BARRIER OPTIONS}

There may be periods during which investors require full protection. This should not imply that they have to turn to the vanilla options market and thus lose the benefits of introducing knock-out barrier provisions in their contract. There are also investors who wish to maximise the leverage effect of options and who might want to give themselves the opportunity of knocking-in during only a fraction of the option life. Partial-time step double barrier options allow that extra flexibility, unlike regular step double barrier options. Indeed, they make it possible to combine periods with and without barriers up until expiry, thus reaching out to a broader set of investors.

In line with the usual terminology, a TSDKO or TSDKI option is said to be early-ending when monitoring of the two-step double barrier starts at the contract's inception and ends before expiry. More specifically, at the option expiry $t_{3}$, an early-ending two-step double knock-out (resp. knock-in) option, or EETSDKO (resp. EETSDKI) option, has the same payoff as a standard call or put on condition that the underlying asset price $S_{t}$ has hit neither (resp. either) the first upper barrier $\mathrm{U}_{1}$ nor (resp. or) the first lower barrier $\mathrm{D}_{1}$ during the time interval $\left[\mathrm{t}_{0} ; \mathrm{t}_{1}\right]$, and (resp. or) that it has hit neither (resp. either) the second upper barrier $\mathrm{U}_{2}$ nor (resp. or) the second lower barrier $\mathrm{D}_{2}$ during the

time interval $\left[\mathrm{t}_{1} ; \mathrm{t}_{2}\right]$ with $\mathrm{t}_{0}=0 \leq \mathrm{t}_{1} \leq \mathrm{t}_{2} \leq \mathrm{t}_{3}$. A TSDKO or TSDKI option is said to be forwardstart when monitoring the two-step double barrier starts after the contract's inception and ends at expiry. More specifically, at the option expiry $t_{3}$, a forward-start two-step double knock-out (resp. knock-in) option, or FSTSDKO (resp. FSTSDKI) option, has the same payoff as a standard call or put on condition that the underlying asset price $S_{t}$ has hit neither (resp. either) the first upper barrier $\mathrm{U}_{1}$ nor (resp. or) the first lower barrier $\mathrm{D}_{1}$ during the time interval $\left[\mathrm{t}_{1} ; \mathrm{t}_{2}\right]$, and (resp. or) that it has hit neither (resp. either) the second upper barrier $\mathrm{U}_{2}$ nor (resp. or) the second lower barrier $\mathrm{D}_{2}$ during the time interval $\left[t_{2} ; t_{3}\right]$, with $t_{0}=0 \leq t_{1} \leq t_{2} \leq t_{3}$. Closed form formulae for early-ending and 
forward-start two-step double barrier options are provided in Proposition 2 and Proposition 3 of Appendix 1. When $t_{2}$ tends to $t_{3}$, Proposition 2 converges to Proposition 1 . When $t_{1}$ tends to $t_{0}$, Proposition 3 converges to Proposition 1.

A partial-time TSDKO option will always be more valuable than the corresponding regular TSDKO option (i.e., the TSDKO option with the two-step double barrier covering the entire option life), because the former involves fewer chances of knocking-out. A partial-time TSDKI option will always be less expensive than the corresponding regular TSDKI option, because the former provides fewer opportunities of knocking-in.

Exhibit 6 shows the realised yield on long positions in four kinds of at-the-money call options for various levels of the underlying asset at expiry, under the assumption that the knock-in options have been activated; volatility is set at an "intermediary" level (30\%) and maturity is one year. The more stringent the conditions for knocking-in, the lower the option premium, the higher the realised return on investment.

Because the probability that exit points will be hit increases with time to maturity, the location of the double barrier at the end of the option life rather than at its beginning tends to make knock-out instruments less valuable. The opposite is true for knock-in instruments. In other words, an EETSDKO option is often more valuable than the corresponding FSTSDKO option with the same parameters and contract specifications except for the location of the two-step double barrier in time, while a FSTSDKI option is often more valuable than than the corresponding EETSDKI option. This claim was numerically tested by comparing 1,000,000 EETSDKO and FSTSDKO put option values, each time with randomly chosen parameters, barrier levels and strikes. In every case, the same set of parameters and contract specifications was used to value both types of options, the only difference being the location of the two-step double barrier in time. It turned out that FSTSDKO put prices were greater than EETSDKO put prices in only $6,49 \%$ of all computed cases. When the EETSDKO call option is specified to have a shrinking two-step double barrier (that is, $\mathrm{D}_{2} \geq \mathrm{D}_{1}$ and $\mathrm{U}_{2} \leq \mathrm{U}_{1}$ ) and the FSTSDKO call option is specified to have the symmetrical widening two-step double barrier (that is, $\left[\mathrm{D}_{2} ; \mathrm{U}_{2}\right]$ is monitored prior to $\left[\mathrm{D}_{1} ; \mathrm{U}_{1}\right]$ ), the proportion of FSTSDKO put prices that are greater than EETSDKO put prices increases to $14.63 \%$, which suggests that the ordering of the double barriers is not negligible, though less significant than with regular TSDKO options.

There is a strong dependency of the early-ending two-step double barrier option value on the distance between $t_{2}$ and $t_{3}$ and of the forward start two-step double barrier option on the distance between $t_{0}$ and $t_{1}$. Take, for instance, a one-year expiry at-the-money knock-out call option with $S(0)=100$, $\mathrm{r}=3 \%, \quad \sigma=30 \%, \quad \delta=0, \quad\left[\mathrm{D}_{1}=80 ; \mathrm{U}_{1}=120\right] \quad$ monitored over $\quad\left[\mathrm{t}_{0} ; \mathrm{t}_{1}=0.125\right], \quad$ and $\left[\mathrm{D}_{2}=75 ; \mathrm{U}_{2}=125\right]$ monitored over $\left[\mathrm{t}_{1}=0.125 ; \mathrm{t}_{2}=0.25\right]$. The distance between $\mathrm{t}_{2}$ and $\mathrm{t}_{3}$ is thus $75 \%$ of the total option life. The value of the option is then equal to 8.71. Take now the same option 
without early-ending feature (which has a negative effect on the premium) but with a wider double barrier (which has a positive effect on the premium); more specifically, we now have $\left[\mathrm{D}_{1}=70 ; \mathrm{U}_{1}=130\right]$ monitored over $\left[\mathrm{t}_{0} ; \mathrm{t}_{1}=0.5\right]$, and $\left[\mathrm{D}_{2}=60 ; \mathrm{U}_{2}=140\right]$ monitored over $\left[t_{1}=0.5 ; t_{2}=\right.$ expiry $\left.=1\right]$. The distance between $t_{2}$ and $t_{3}$ is now zero. The option premium then plummets to 2.642, despite the fact that the new knock-out double barriers are much further from the spot. The loss in value due to the elimination of the early-ending feature greatly supersedes the gain in value due to wider knock-out barriers. Now, take $\left[\mathrm{D}_{1}=80 ; \mathrm{U}_{1}=120\right]$ monitored over $\left[\mathrm{t}_{0} ; \mathrm{t}_{1}=0.25\right]$, and $\left[\mathrm{D}_{2}=75 ; \mathrm{U}_{2}=125\right]$ monitored over $\left[\mathrm{t}_{1}=0.25 ; \mathrm{t}_{2}=0.5\right]$, that is, the initial barriers over two quarters of the option life instead of one. The option premium then stands at 4.02. In other words, the option value is more than halved as a consequence of the extension of the monitoring period on $25 \%$ of the total option life.

Compared with regular two-step double knock-out options, an increase in the volatility of the underlying asset will exert a stronger effect on the likelihood of expiring in-the-money than on the risk of knocking-out, especially if the two-step double barrier is early-ending. Exhibit 7 presents the prices of far out-of-the-money six-month expiry vanilla call options, TSDKO call options and EETSDKO call options for two different levels of volatility of the underlying asset. When volatility is just $15 \%$, all call option prices are close to zero, whether knock-out provisions are included in the contract or not, because the fluctuations in the asset price are too subdued for a significant number of asset price paths to travel the distance from the spot to the strike within only six months. When volatility is $30 \%$, the value of the vanilla call soars from almost zero to 2.82. In contrast, the value of the TSDKO call decreases to even less than it was before. This can only be explained by the increase in the probability of knocking-out, whose impact outweighs that of the increase in the probability of ending above the strike at expiry. The EETSDKO call, however, behaves much more like a vanilla call, since its value rises to as much as 1.6165. It is clear, in this simple numerical example, that making the two-step double barrier early-ending significantly reverses the option's relative sensitivities to the chances of knocking-out and of ending above the strike at expiry.

Finally, let us emphasize that it might not suit investors either to start the step double barrier at the beginning of the option life or to end the step double barrier at the option expiry. In general, it will be specified that monitoring starts at some point after $t_{0}$ and stops at some point before expiry. Such a specification is often referred to as a "window". At the option expiry $t_{4}$, a window two-step double knock-out (resp. knock-in) option, or WTSDKO (resp. WTSDKI) option, has the same payoff as a standard call or put on condition that the underlying asset price $S_{t}$ has hit neither (resp. either) the first upper barrier $\mathrm{U}_{1}$ nor (resp. or) the first lower barrier $\mathrm{D}_{1}$ during the time interval $\left[\mathrm{t}_{1} ; \mathrm{t}_{2}\right]$, and (resp. or) that it has hit neither (resp. either) the second upper barrier $U_{2}$ nor (resp. or) the second lower 
barrier $\mathrm{D}_{2}$ during the time interval $\left[\mathrm{t}_{2} ; \mathrm{t}_{3}\right]$ with $\mathrm{t}_{0} \leq \mathrm{t}_{1} \leq \mathrm{t}_{2} \leq \mathrm{t}_{3} \leq \mathrm{t}_{4}$. A formula for the fair value of such an option is provided in Proposition 4 of Appendix 1. When $t_{1}$ tends to $t_{0}$, Proposition 4 converges to Proposition 2. When $t_{3}$ tends to $t_{4}$, Proposition 4 converges to Proposition 3 . When $t_{1}$ tends to $t_{0}$ and $t_{3}$ tends to $t_{4}$, Proposition 4 tends to Proposition 1 .

\section{RAINBOW STEP DOUBLE BARRIER OPTIONS}

It is not necessary to assume that the asset price which is compared with the strike price at the option expiry is the same as the one whose fluctuations are monitored before expiry. It can be useful to distinguish them. For example, you may be bullish on an asset $\mathrm{X}$ that has a high implied volatility. Buying a vanilla call will be expensive. Buying a knock-out step double barrier call will be risky, unless you widen the permitted ranges of fluctuations to such an extent that you will end up with a premium that is not significantly different from that of a vanilla call. Buying a knock-in step double barrier call is a possibility, but it is quite a speculative strategy. If you can find another asset $\mathrm{Y}$ with a lower volatility, then a more suitable investment would be a long position in an option that pays off the difference, if positive, between $\mathrm{X}$ and the strike price, provided that $\mathrm{Y}$ has remained within prespecified ranges. This will be less expensive than a long position in a vanilla call on $\mathrm{X}$ and less risky than a long position in either a knock-out step double barrier call or a knock-in step double barrier call on $\mathrm{X}$. This type of instrument is also useful for hedging purposes, especially when several currencies are involved. For instance, if you are due to receive the proceeds of an investment in an asset $\mathrm{X}$ denominated in a foreign currency at a given future date, then you might want to hold a long position in a put option written on $\mathrm{X}$ with a double barrier monitored with respect to the relevant exchange rate.

Outside step double barrier options are designed to meet the previous requirements. More specifically, at the option expiry $t_{2}$, an outside two-step double knock-out (resp. knock-in) option, or OTSDKO (resp. OTSDKI) option, has the same payoff as a standard call or put on a given asset $S^{(2)}$, provided that another asset $S^{(1)}$ has hit neither (resp. either) an upper barrier $\mathrm{U}_{1}$ nor (resp. or) a lower barrier $\mathrm{D}_{1}$ during the time interval $\left[\mathrm{t}_{0} ; \mathrm{t}_{1}\right]$, and (resp. or) that it has hit neither (resp. either) an upper barrier $\mathrm{U}_{2}$ nor (resp. or) a lower barrier $\mathrm{D}_{2}$ during the time interval $\left[\mathrm{t}_{1} ; \mathrm{t}_{2}\right]$ with $\mathrm{t}_{0}=0 \leq \mathrm{t}_{1} \leq \mathrm{t}_{2}$. A regular two-step double barrier option is nested when the correlation between $S^{(1)}$ and $S^{(2)}$ tends to 1 and the volatility of $S^{(1)}$ is equal to the volatility of $S^{(2)}$. Early-ending outside two-step double barrier options (denoted by EEOTSDKO and EEOTSDKI) as well as forward-start outside two-step double barrier options (denoted by FSOTSDKO and FSOTSDKI) can be defined in a similar manner. 
Closed form formulae for the valuation of outside two-step double barrier options and early-ending outside two-step double barrier options are provided in Proposition 5 and Proposition 6 of Appendix 1. Suppose you want to be long an at-the-money call option on an asset $\mathrm{X}$ whose spot value is 100 , with six-month expiry, riskless rate equal to $3 \%$, no dividends and a volatility of $45 \%$. The Black-Scholes value of this option is 13,305 . You could obtain a substantial premium reduction by introducing, for instance, the following two-step double knock-out barrier : $\left[\mathrm{D}_{1}=75 ; \mathrm{U}_{1}=125\right]$ over $\left[\mathrm{t}_{0} ; \mathrm{t}_{1}=0.25\right]$, and $\left[\mathrm{D}_{1}=70 ; \mathrm{U}_{1}=130\right]$ over $\left[\mathrm{t}_{1}=0.25 ; \mathrm{t}_{2}=0.5\right]$. But, due to the high volatility of asset price $\mathrm{X}$, the risk you incur would dramatically increase. Indeed, the risk-neutral probability of knocking-out would then be as high as $88.96 \%$, which would be deemed as unacceptable by a vast majority of investors. Now suppose you can find a traded asset $\mathrm{Y}$ which is strongly positively correlated with $\mathrm{X}$ but much less volatile. This asset $\mathrm{Y}$ will tend to move in the same direction as $\mathrm{X}$ but its fluctuations will be of smaller sizes. More specifically, set the volatility of $\mathrm{Y}$ at $15 \%$ and its constant coefficient of correlation with $\mathrm{X}$ at $80 \%$. Assume, without loss of generality, that the spot value of $\mathrm{Y}$ is the same as that of X. Then, the price of an outside two-step double knock-out call option with the previous twostep double knock-out barrier now monitored with respect to Y, significantly decreases from 13,305 to 10.329. In exchange for this premium reduction, the risk incurred by the option holder only moderately increases compared with a long position in a vanilla call option. Indeed, the risk-neutral probability that the asset $\mathrm{X}$ will be above the strike at expiry is $45.543 \%$, while the risk-neutral probability that the asset $\mathrm{X}$ will be above the strike at expiry and that the asset $\mathrm{Y}$ will remain within the permitted range is $40.834 \%$. These effects are very sensitive to the correlation between $\mathrm{X}$ and $\mathrm{Y}$. If the correlation coefficient between $\mathrm{X}$ and $\mathrm{Y}$ is $-80 \%$ instead of $80 \%$, the price differential with a vanilla call shrinks to $4.58 \%$ instead of being equal to $22.37 \%$. In general, correlation effects can be simply measured by comparing the price of a regular two-step double barrier option and the price of the corresponding outside two-step double-barrier option with the same volatility for the two underlying assets.

Another way to exploit differences in volatility among traded assets is to design a contract whereby the first double barrier is monitored with respect to an asset $\mathrm{X}$ while the second double barrier is monitored with respect to another asset Y. More specifically, a two-asset two-step double knock-out (resp. knock-in) option, or TATSDKO (resp. TATSDKI) option, has the same payoff as a standard call or put on a given asset $S^{(2)}$ at expiry $\mathrm{t}_{2}$, provided that another asset $S^{(1)}$ has hit neither (resp. either) an upper barrier $\mathrm{U}_{1}$ nor (resp. or) a lower barrier $\mathrm{D}_{1}$ during the time interval $\left[\mathrm{t}_{0} ; \mathrm{t}_{1}\right]$, and (resp. or) that $S^{(2)}$ has hit neither (resp. either) an upper barrier $\mathrm{U}_{2}$ nor (resp. or) a lower barrier $\mathrm{D}_{2}$ during the time interval $\left[t_{1} ; t_{2}\right]$ with $t_{0}=0 \leq t_{1} \leq t_{2}$. A closed form formula for the valuation of a two-asset two-step double barrier option is provided in Proposition 7 of Appendix 1. Notice that, as $t_{1}$ tends to $t_{2}$, a TATSDKO option tends to an OTSDKO option; as $U_{2}$ becomes very high and $D_{2}$ becomes 
very low, a TATSDKO option tends to an early-ending outside double knock-out option; as $\mathrm{U}_{1}$ becomes very high and $\mathrm{D}_{1}$ becomes very low, a TATSDKO option tends to a forward-start double knock-out option. But a two-asset two-step double barrier option cannot converge to a regular twostep double barrier option, unless the correlation between $S^{(1)}$ and $S^{(2)}$ tends to 1 and the volatility of $S^{(1)}$ is equal to the volatility of $S^{(2)}$, as with outside two-step double barrier options.

If you pick two traded assets $\mathrm{X}$ and $\mathrm{Y}$ such that $\mathrm{Y}$ is significantly less volatile than $\mathrm{X}$, you will substantially lower your risk exposure, relative to a long position in a regular TSDKO call, by holding a TATSDKO call written on $\mathrm{X}$ over $\left[\mathrm{t}_{0} ; \mathrm{t}_{1}\right]$ and on $\mathrm{Y}$ over $\left[\mathrm{t}_{1} ; \mathrm{t}_{2}\right]$. The effect will be more pronounced if $\mathrm{Y}$ is strongly positively correlated with $\mathrm{X}$, though, overall, correlation has less impact on TATSDKO and TATSDKI options than on OTSDKO and OTSDKI options. The downside is that your chances of ending in-the-money at expiry also diminish. You can avoid this adverse side-effect by specifying that the two-step double barrier will be monitored with respect to the less volatile asset in the first part of the option life. You can then manage your risk exposure by widening the second step of your double barrier. Suppose, as in the previous example, that asset $X$ has a volatility of $45 \%$ and asset $\mathrm{Y}$ has a volatility of $15 \%$, while both assets have spot value equal to 100 and the riskless rate is $3 \%$. We know that a regular TSDKO call written on $\mathrm{X}$ will not be worth much, unless the double barrier is extremely wide. Now write a TATSDKO call contract in which you have $\left[\mathrm{D}_{1}=80 ; \mathrm{U}_{1}=120\right]$ monitored with respect to $\mathrm{Y}$ over $\left[\mathrm{t}_{0} ; \mathrm{t}_{1}=0.25\right]$ and $\left[\mathrm{D}_{2}=40 ; \mathrm{U}_{2}=160\right]$ monitored with respect to $\mathrm{X}$ over $\left[\mathrm{t}_{1}=0.25 ; \mathrm{t}_{2}=0.5\right]$. Although the first step of the double barrier is very narrow, the risk-neutral probability of knocking-out is only $18.96 \%$. At the same time, the probability that the option will end in-the-money at expiry conditional on the option not having been knocked-out is as high as with a vanilla option. And yet, the premium of the TATSDKO call ranges roughly from 6.1 to 6.4 , depending on the value of the correlation between $\mathrm{X}$ and $\mathrm{Y}$, which is always less than half the premium of the vanilla call.

\section{CONCLUSION}

In this paper, step double barrier options are studied and analytically valued. The main attraction of these instruments is that they are more flexible than regular double barrier options. One limitation, though, is that knock-out and knock-in provisions must be prespecified in the option contract. A useful extension would consist in allowing to reset barrier levels during the option life, so that the contract terms can be adjusted according to realized changes in the market or to new anticipations on the part of market participants. Indeed, a number of range notes structured in the market include the possibility to define a new range during the option life, usually when a knock-out barrier has been hit prior to expiry, thus giving investors an extra chance to receive the enhanced yield. They are often referred to 
as resettable range notes. If the resetting rule is not automatic but left to the discretion of the investor, the possibility of analytical pricing is lost, because we now face a free boundary problem. However, it is not difficult to modify the valuation formulae provided in this paper to include the possibility to change the second step of the double barrier depending on the level of the underlying asset. Basically, all that it takes is to define several levels of the second step of the double barrier matching several possible ranges for the value of the underlying asset at the time the double barrier changes. Then, the formulae provided in Appendix 1 can be used with minor modifications to value the options embedded in resettable range notes.

\section{APPENDIX 1}

This appendix lists seven formulae that enable to compute in closed form the no-arbitrage values of the step double barrier options defined in sections 1,2 and 3, assuming that asset price processes are geometric Brownian motions with constant parameters. Proving these formulae in full details requires cumbersome calculations that cannot be reproduced here. An outline of the proofs can be accessed on the JOD Website.

Only formulae for knock-out options are provided, as knock-in option prices are obtained simply by taking the difference between vanilla option prices and knock-out option prices.

The following notations apply to the remainder of this appendix :

- $S_{0}$ is the spot value of the underlying asset $S$

$-r$ is the riskless rate

- $\sigma$ is the volatility of $S$

- $\delta$ is a continuous rate paid out by $S$

- $K$ is the strike price

- $\left[D_{i}, U_{i}\right]$ is the $\mathrm{i}$-th step of the double barrier, with $D_{i}$ as the lower bound and $U_{i}$ as the upper bound

- $t_{2}$ is the option expiry in Proposition 1, 5 and 7

- $t_{3}$ is the option expiry in Proposition 2, 3 and 6

- $t_{4}$ is the option expiry in Proposition 4

- $S_{0}^{(1)}$ and $S_{0}^{(2)}$ in Proposition 5, 6 and 7 are the spot values of the underlying assets $S^{(1)}$ and $S^{(2)}$ respectively

- $\sigma_{1}$ and $\sigma_{2}$ in Proposition 5, 6 and 7 are the volatilities of $S^{(1)}$ and $S^{(2)}$ respectively

- $\delta_{1}$ and $\delta_{2}$ in Proposition 5, 6 and 7 are continuous rates paid out by $S^{(1)}$ and $S^{(2)}$ respectively

- $\rho$ in Proposition 5, 6 and 7 is the correlation coefficient between $S^{(1)}$ and $S^{(2)}$

The following proposition states the no-arbitrage value of a two-step double knock-out put as defined in Section 1. 


\section{Proposition 1}

The no-arbitrage value of a two-step double knock-out put (TSDKOP) is given by:

$$
\begin{aligned}
& \operatorname{TSDKOP}\left(S_{0}, \sigma, r, \delta, t_{1}, t_{2}, K, U_{1}, U_{2}, D_{1}, D_{2}\right) \\
& =\exp \left(-r t_{2}\right) K \Phi_{\mathrm{TS}}\left(\mu=r-\delta-\sigma^{2} / 2\right)-\exp \left(-\delta t_{2}\right) S_{0} \Phi_{\mathrm{TS}}\left(\mu=r-\delta+\sigma^{2} / 2\right)
\end{aligned}
$$

where the function $\Phi_{\mathrm{TS}}(\mu)$ is defined as follows :

$\Phi_{\mathrm{TS}}(\mu)=$

$$
\begin{aligned}
& \sum_{n_{1}=-\infty}^{\infty} \sum_{n_{2}=-\infty}^{\infty}\left(\frac{U_{1}^{n_{1}} U_{2}^{n_{2}}}{D_{1}^{n_{1}} D_{2}^{n_{2}}}\right)^{\frac{2 \mu}{\sigma^{2}}}\left\{\begin{array}{l}
N_{2}\left[\mathrm{I}_{1}\left(U_{1} \wedge U_{2}\right), \mathrm{I}_{2}(K) ; \sqrt{\frac{t_{1}}{t_{2}}}\right]-N_{2}\left[\mathrm{I}_{1}\left(D_{1} \vee D_{2}\right), \mathrm{I}_{2}(K) ; \sqrt{\frac{t_{1}}{t_{2}}}\right] \\
\left.-N_{2}\left[\mathrm{I}_{1}\left(U_{1} \wedge U_{2}\right), \mathrm{I}_{2}\left(D_{2}\right) ; \sqrt{\frac{t_{1}}{t_{2}}}\right]+N_{2}\left[\mathrm{I}_{1}\left(D_{1} \vee D_{2}\right), \mathrm{I}_{2}\left(D_{2}\right) ; \sqrt{\frac{t_{1}}{t_{2}}}\right]\right\}
\end{array}\right. \\
& -\sum_{n_{1}=-\infty}^{\infty} \sum_{n_{2}=-\infty}^{\infty}\left(\frac{D_{1}^{n_{1}} D_{2}^{n_{2}+1}}{S_{0} U_{1}^{n_{1}} U_{2}^{n_{2}}}\right)^{\frac{2 \mu}{\sigma^{2}}}\left\{\begin{array}{l}
N_{2}\left[\mathrm{I}_{3}\left(U_{1} \wedge U_{2}\right), \mathrm{I}_{4}(K) ;-\sqrt{\frac{t_{1}}{t_{2}}}\right]-N_{2}\left[\mathrm{I}_{3}\left(D_{1} \vee D_{2}\right), \mathrm{I}_{4}(K) ;-\sqrt{\frac{t_{1}}{t_{2}}}\right] \\
-N_{2}\left[\mathrm{I}_{3}\left(U_{1} \wedge U_{2}\right), \mathrm{I}_{4}\left(D_{2}\right) ;-\sqrt{\frac{t_{1}}{t_{2}}}\right]+N_{2}\left[\mathrm{I}_{3}\left(D_{1} \vee D_{2}\right), \mathrm{I}_{4}\left(D_{2}\right) ;-\sqrt{\frac{t_{1}}{t_{2}}}\right]
\end{array}\right\} \\
& -\sum_{n_{1}=-\infty}^{\infty} \sum_{n_{2}=-\infty}^{\infty}\left(\frac{D_{1}^{n_{1}+1} U_{2}^{n_{2}}}{S_{0} U_{1}^{n_{1}} D_{2}^{n_{2}}}\right)^{\frac{2 \mu}{\sigma^{2}}}\left\{\begin{array}{l}
N_{2}\left[\mathrm{I}_{5}\left(U_{1} \wedge U_{2}\right), \mathrm{I}_{6}(K) ; \sqrt{\frac{t_{1}}{t_{2}}}\right]-N_{2}\left[\mathrm{I}_{5}\left(D_{1} \vee D_{2}\right), \mathrm{I}_{6}(K) ; \sqrt{\frac{t_{1}}{t_{2}}}\right] \\
\left.-N_{2}\left[\mathrm{I}_{5}\left(U_{1} \wedge U_{2}\right), \mathrm{I}_{6}\left(D_{2}\right) ; \sqrt{\frac{t_{1}}{t_{2}}}\right]+N_{2}\left[\mathrm{I}_{5}\left(D_{1} \vee D_{2}\right), \mathrm{I}_{6}\left(D_{2}\right) ; \sqrt{\frac{t_{1}}{t_{2}}}\right]\right\}
\end{array}\right. \\
& +\sum_{n_{1}=-\infty}^{\infty} \sum_{n_{2}=-\infty}^{\infty}\left(\frac{D_{2}^{n_{2}+1} U_{1}^{n_{1}}}{D_{1}^{n_{1}+1} U_{2}^{n_{2}}}\right)^{\frac{2 \mu}{\sigma^{2}}}\left\{\begin{array}{l}
N_{2}\left[\mathrm{I}_{7}\left(U_{1} \wedge U_{2}\right), \mathrm{I}_{8}(K) ;-\sqrt{\frac{t_{1}}{t_{2}}}\right]-N_{2}\left[\mathrm{I}_{7}\left(D_{1} \vee D_{2}\right), \mathrm{I}_{8}(K) ;-\sqrt{\frac{t_{1}}{t_{2}}}\right] \\
-N_{2}\left[\mathrm{I}_{7}\left(U_{1} \wedge U_{2}\right), \mathrm{I}_{8}\left(D_{2}\right) ;-\sqrt{\frac{t_{1}}{t_{2}}}\right]+N_{2}\left[\mathrm{I}_{7}\left(D_{1} \vee D_{2}\right), \mathrm{I}_{8}\left(D_{2}\right) ;-\sqrt{\frac{t_{1}}{t_{2}}}\right]
\end{array}\right\}
\end{aligned}
$$

where $N_{2}\left[., . ; \theta_{12}\right]$ is the joint cumulative distribution function of two standard normal random variables $Y_{1}$ and $Y_{2}$ with $\theta_{12}$ as correlation coefficient, and where the remaining functions are defined as follows:

$$
\begin{aligned}
& \mathrm{I}_{1}(X)=\left(\ln \left(\frac{X D_{1}^{2 n_{1}}}{S_{0} U_{1}^{2 n_{1}}}\right)-\mu t_{1}\right) / \sigma \sqrt{t_{1}}, \mathrm{I}_{2}(X)=\left(\ln \left(\frac{X D_{2}^{2 n_{2}} D_{1}^{2 n_{1}}}{S_{0} U_{2}^{2 n_{2}} U_{1}^{2 n_{1}}}\right)-\mu t_{2}\right) / \sigma \sqrt{t_{2}} \\
& \mathrm{I}_{3}(X)=\left(\ln \left(\frac{X D_{1}^{2 n_{1}}}{S_{0} U_{1}^{2 n_{1}}}\right)+\mu t_{1}\right) / \sigma \sqrt{t_{1}}, \mathrm{I}_{4}(X)=\left(\ln \left(\frac{X S_{0} U_{2}^{2 n_{2}} U_{1}^{2 n_{1}}}{D_{2}^{2\left(n_{2}+1\right)} D_{1}^{2 n_{1}}}\right)-\mu t_{2}\right) / \sigma \sqrt{t_{2}} \\
& \mathrm{I}_{5}(X)=\left(\ln \left(\frac{X S_{0} U_{1}^{2 n_{1}}}{D_{1}^{2\left(n_{1}+1\right)}}\right)-\mu t_{1}\right) / \sigma \sqrt{t_{1}}, \mathrm{I}_{6}(X)=\left(\ln \left(\frac{X S_{0} D_{2}^{2 n_{2}} U_{1}^{2 n_{1}}}{D_{1}^{2\left(n_{1}+1\right)} U_{2}^{2 n_{2}}}\right)-\mu t_{2}\right) / \sigma \sqrt{t_{2}} \\
& \mathrm{I}_{7}(X)=\left(\ln \left(\frac{X S_{0} U_{1}^{2 n_{1}}}{D_{1}^{2\left(n_{1}+1\right)}}\right)+\mu t_{1}\right) / \sigma \sqrt{t_{1}} \mathrm{I}_{8}(X)=\left(\ln \left(\frac{X D_{1}^{2\left(n_{1}+1\right)} U_{2}^{2 n_{2}}}{S_{0} D_{2}^{2\left(n_{2}+1\right)} U_{1}^{2 n_{1}}}\right)-\mu t_{2}\right) / \sigma \sqrt{t_{2}}
\end{aligned}
$$


The numerical implementation of Proposition 1 is easy using the Genz algorithm (Genz [2004]) to compute the bivariate standard normal cumulative distribution functions. The infinite sums converge very quickly, so that their truncation to $n_{1}=-8 \ldots 8$ and $n_{2}=-8 \ldots 8$ entails negligible loss of precision for all practical purposes. It takes less than one second to compute the price of a TSDKOP by means of Proposition 1 on an ordinary personal computer.

The value of a two-step double knock-out call, TSDKOC, is obtained as follows :

$$
\begin{aligned}
& \operatorname{TSDKOC}\left(S_{0}, \sigma, r, \delta, t_{1}, t_{2}, K, U_{1}, U_{2}, D_{1}, D_{2}\right) \\
& =\operatorname{TSDKOP}\left(S_{0}, \sigma, r, \delta, t_{1}, t_{2}, U_{2}, U_{1}, U_{2}, D_{1}, D_{2}\right)-\operatorname{TSDKOP}\left(S_{0}, \sigma, r, \delta, t_{1}, t_{2}, K, U_{1}, U_{2}, D_{1}, D_{2}\right)
\end{aligned}
$$

The next proposition states the no-arbitrage value of an early-ending two-step double knock-out put as defined in Section 2.

\section{Proposition 2}

The no-arbitrage value of an early-ending two-step double knock-out put (EETSDKOP) is given by:

$$
\begin{aligned}
& \operatorname{EETSDKOP}\left(S_{0}, \sigma, r, \delta, t_{1}, t_{2}, t_{3}, K, U_{1}, U_{2}, D_{1}, D_{2}\right) \\
& =\exp \left(-r t_{3}\right) K \Phi_{\mathrm{EETS}}\left(\mu=r-\delta-\sigma^{2} / 2\right)-\exp \left(-\delta t_{3}\right) S_{0} \Phi_{\text {EETS }}\left(\mu=r-\delta+\sigma^{2} / 2\right)
\end{aligned}
$$

where the function $\Phi_{\mathrm{EETS}}(\mu)$ is defined as follows :

$$
\begin{aligned}
& \Phi_{\text {EETS }}(\mu)= \\
& \sum_{n_{1}=-\infty}^{\infty} \sum_{n_{2}=-\infty}^{\infty}\left(\frac{U_{1}^{n_{1}} U_{2}^{n_{2}}}{D_{1}^{n_{1}} D_{2}^{n_{2}}}\right)^{\frac{2 \mu}{\sigma^{2}}} \\
& \left\{\begin{array}{l}
N_{3}\left[\mathrm{I}_{1}\left(U_{1} \wedge U_{2}\right), \mathrm{I}_{2}\left(U_{2}\right), \mathrm{I}_{3}(K) ; \mathrm{H}_{1}\right]-N_{3}\left[\mathrm{I}_{1}\left(D_{1} \vee D_{2}\right), \mathrm{I}_{2}\left(U_{2}\right), \mathrm{I}_{3}(K) ; \mathrm{H}_{1}\right] \\
-N_{3}\left[\mathrm{I}_{1}\left(U_{1} \wedge U_{2}\right), \mathrm{I}_{2}\left(D_{2}\right), \mathrm{I}_{3}(K) ; \mathrm{H}_{1}\right]+N_{3}\left[\mathrm{I}_{1}\left(D_{1} \vee D_{2}\right), \mathrm{I}_{2}\left(D_{2}\right), \mathrm{I}_{3}(K) ; \mathrm{H}_{1}\right]
\end{array}\right\} \\
& -\sum_{n_{1}=-\infty}^{\infty} \sum_{n_{2}=-\infty}^{\infty}\left(\frac{D_{1}^{n_{1}} D_{2}^{n_{2}+1}}{S_{0} U_{1}^{n_{1}} U_{2}^{n_{2}}}\right) \frac{2 \mu}{\sigma^{2}} \\
& \left\{\begin{array}{l}
N_{3}\left[\mathrm{I}_{4}\left(U_{1} \wedge U_{2}\right), \mathrm{I}_{5}\left(U_{2}\right), \mathrm{I}_{6}(K) ; \mathrm{H}_{2}\right]-N_{3}\left[\mathrm{I}_{4}\left(D_{1} \vee D_{2}\right), \mathrm{I}_{5}\left(U_{2}\right), \mathrm{I}_{6}(K) ; \mathrm{H}_{2}\right] \\
-N_{3}\left[\mathrm{I}_{4}\left(U_{1} \wedge U_{2}\right), \mathrm{I}_{5}\left(D_{2}\right), \mathrm{I}_{6}(K) ; \mathrm{H}_{2}\right]+N_{3}\left[\mathrm{I}_{4}\left(D_{1} \vee D_{2}\right), \mathrm{I}_{5}\left(D_{2}\right), \mathrm{I}_{6}(K) ; \mathrm{H}_{2}\right]
\end{array}\right\} \\
& -\sum_{n_{1}=-\infty}^{\infty} \sum_{n_{2}=-\infty}^{\infty}\left(\frac{D_{1}^{n_{1}+1} U_{2}^{n_{2}}}{S_{0} U_{1}^{n_{1}} D_{2}^{n_{2}}}\right) \\
& \left\{\begin{array}{l}
N_{3}\left[\mathrm{I}_{7}\left(U_{1} \wedge U_{2}\right), \mathrm{I}_{8}\left(U_{2}\right), \mathrm{I}_{9}(K) ; \mathrm{H}_{1}\right]-N_{3}\left[\mathrm{I}_{7}\left(D_{1} \vee D_{2}\right), \mathrm{I}_{8}\left(U_{2}\right), \mathrm{I}_{9}(K) ; \mathrm{H}_{1}\right] \\
-N_{3}\left[\mathrm{I}_{7}\left(U_{1} \wedge U_{2}\right), \mathrm{I}_{8}\left(D_{2}\right), \mathrm{I}_{9}(K) ; \mathrm{H}_{1}\right]+N_{3}\left[\mathrm{I}_{7}\left(D_{1} \vee D_{2}\right), \mathrm{I}_{8}\left(D_{2}\right), \mathrm{I}_{9}(K) ; \mathrm{H}_{1}\right]
\end{array}\right\} \\
& +\sum_{n_{1}=-\infty}^{\infty} \sum_{n_{2}=-\infty}^{\infty}\left(\frac{D_{2}^{n_{2}+1} U_{1}^{n_{1}}}{D_{1}^{n_{1}+1} U_{2}^{n_{2}}}\right)
\end{aligned}
$$




$$
\left\{\begin{array}{l}
N_{3}\left[\mathrm{I}_{10}\left(U_{1} \wedge U_{2}\right), \mathrm{I}_{11}\left(U_{2}\right), \mathrm{I}_{12}(K) ; \mathrm{H}_{2}\right]-N_{3}\left[\mathrm{I}_{10}\left(D_{1} \vee D_{2}\right), \mathrm{I}_{11}\left(U_{2}\right), \mathrm{I}_{12}(K) ; \mathrm{H}_{2}\right] \\
-N_{3}\left[\mathrm{I}_{10}\left(U_{1} \wedge U_{2}\right), \mathrm{I}_{11}\left(D_{2}\right), \mathrm{I}_{12}(K) ; \mathrm{H}_{2}\right]+N_{3}\left[\mathrm{I}_{10}\left(D_{1} \vee D_{2}\right), \mathrm{I}_{11}\left(D_{2}\right), \mathrm{I}_{12}(K) ; \mathrm{H}_{2}\right]
\end{array}\right\}
$$

where $N_{3}\left[., ., . ; \theta_{12}, \theta_{13}, \theta_{23}\right]$ is the joint cumulative distribution function of three standard normal random variables $Y_{1}, Y_{2}$, and $Y_{3}$ with $\theta_{12}$ as correlation coefficient between $Y_{1}$ and $Y_{2}, \theta_{13}$ as correlation coefficient between $Y_{1}$ and $Y_{3}$, and $\theta_{23}$ as correlation coefficient $Y_{2}$ and $Y_{3}$, and where the remaining functions are defined as follows:

$$
\begin{aligned}
& \mathrm{I}_{1}(X)=\left(\ln \left(\frac{X D_{1}^{2 n_{1}}}{S_{0} U_{1}^{2 n_{1}}}\right)-\mu t_{1}\right) / \sigma \sqrt{t_{1}}, \mathrm{I}_{2}(X)=\left(\ln \left(\frac{X D_{2}^{2 n_{2}} D_{1}^{2 n_{1}}}{S_{0} U_{2}^{2 n_{2}} U_{1}^{2 n_{1}}}\right)-\mu t_{2}\right) / \sigma \sqrt{t_{2}} \\
& \mathrm{I}_{3}(X)=\left(\ln \left(\frac{X D_{2}^{2 n_{2}} D_{1}^{2 n_{1}}}{S_{0} U_{2}^{2 n_{2}} U_{1}^{2 n_{1}}}\right)-\mu t_{3}\right) / \sigma \sqrt{t_{3}}, \mathrm{I}_{4}(X)=\left(\ln \left(\frac{X D_{1}^{2 n_{1}}}{S_{0} U_{1}^{2 n_{1}}}\right)+\mu t_{1}\right) / \sigma \sqrt{t_{1}} \\
& \mathrm{I}_{5}(X)=\left(\ln \left(\frac{X S_{0} U_{2}^{2 n_{2}} U_{1}^{2 n_{1}}}{D_{2}^{2\left(n_{2}+1\right)} D_{1}^{2 n_{1}}}\right)-\mu t_{2}\right) / \sigma \sqrt{t_{2}}, \mathrm{I}_{6}(X)=\left(\ln \left(\frac{X S_{0} U_{2}^{2 n_{2}} U_{1}^{2 n_{1}}}{D_{2}^{2\left(n_{2}+1\right)} D_{1}^{2 n_{1}}}\right)-\mu t_{3}\right) / \sigma \sqrt{t_{3}} \\
& \mathrm{I}_{7}(X)=\left(\ln \left(\frac{X S_{0} U_{1}^{2 n_{1}}}{D_{1}^{2\left(n_{1}+1\right)}}\right)-\mu t_{1}\right) / \sigma \sqrt{t_{1}}, \mathrm{I}_{8}(X)=\left(\ln \left(\frac{X S_{0} D_{2}^{2 n_{2}} U_{1}^{2 n_{1}}}{D_{1}^{2\left(n_{1}+1\right)} U_{2}^{2 n_{2}}}\right)-\mu t_{2}\right) / \sigma \sqrt{t_{2}} \\
& \mathrm{I}_{9}(X)=\left(\ln \left(\frac{X S_{0} D_{2}^{2 n_{2}} U_{1}^{2 n_{1}}}{D_{1}^{2\left(n_{1}+1\right)} U_{2}^{2 n_{2}}}\right)-\mu t_{3}\right) / \sigma \sqrt{t_{3}}, \mathrm{I}_{10}(X)=\left(\ln \left(\frac{X S_{0} U_{1}^{2 n_{1}}}{D_{1}^{2\left(n_{1}+1\right)}}\right)+\mu t_{1}\right) / \sigma \sqrt{t_{1}} \\
& \mathrm{I}_{11}(X)=\left(\ln \left(\frac{X D_{1}^{2\left(n_{1}+1\right)} U_{2}^{2 n_{2}}}{S_{0} D_{2}^{2\left(n_{2}+1\right)} U_{1}^{2 n_{1}}}\right)-\mu t_{2}\right) / \sigma \sqrt{t_{2}}, \mathrm{I}_{12}(X)=\left(\ln \left(\frac{X D_{1}^{2\left(n_{1}+1\right)} U_{2}^{2 n_{2}}}{S_{0} D_{2}^{2\left(n_{2}+1\right)} U_{1}^{2 n_{1}}}\right)-\mu t_{3}\right) / \sigma \sqrt{t_{3}} \\
& \mathrm{H}_{1}=\left\{\sqrt{\frac{t_{1}}{t_{2}}}, \sqrt{\frac{t_{1}}{t_{3}}}, \sqrt{\frac{t_{2}}{t_{3}}}\right\}, \mathrm{H}_{2}=\left\{-\sqrt{\frac{t_{1}}{t_{2}}},-\sqrt{\frac{t_{1}}{t_{3}}}, \sqrt{\frac{t_{2}}{t_{3}}}\right\}
\end{aligned}
$$

The numerical implementation of Proposition 2 is easy using the Genz algorithm (Genz [2004]) to compute the trivariate standard normal cumulative distribution functions. The infinite sums are truncated, as explained right after Proposition 1. It takes between one and two seconds to compute the price of an EETSDKOP by means of Proposition 2 on an ordinary personal computer.

The value of an early-ending two-step double knock-out call, EETSDKOC, is obtained as follows :

$$
\operatorname{EETSDKOC}\left(S_{0}, \sigma, r, \delta, t_{1}, t_{2}, t_{3}, K, U_{1}, U_{2}, D_{1}, D_{2}\right)
$$

$=\operatorname{EETSDKOP}\left(S_{0}, \sigma, r, \delta, t_{1}, t_{2}, t_{3}, A, U_{1}, U_{2}, D_{1}, D_{2}\right)-\operatorname{EETSDKOP}\left(S_{0}, \sigma, r, \delta, t_{1}, t_{2}, t_{3}, K, U_{1}, U_{2}, D_{1}, D_{2}\right)$ where $A$ is much greater than $S_{0}$ (theoretically, $A \rightarrow \infty$; in practice, take $A$ as six times $S_{0}$ to incur negligible loss of precision for a realistic volatility parameter of the underlying asset).

The next proposition states the no-arbitrage value of a forward-start two-step double knock-out put as defined in Section 2. 


\section{Proposition 3}

The no-arbitrage value of a forward-start two-step double knock-out put (FSTSDKOP) is given by:

$$
\begin{aligned}
& F \operatorname{FSDKOP}\left(S_{0}, \sigma, r, \delta, t_{1}, t_{2}, t_{3}, K, U_{1}, U_{2}, D_{1}, D_{2}\right) \\
& =\exp \left(-r t_{3}\right) K \Phi_{\mathrm{FSTS}}\left(\mu=r-\delta-\sigma^{2} / 2\right)-\exp \left(-\delta t_{3}\right) S_{0} \Phi_{\mathrm{FSTS}}\left(\mu=r-\delta+\sigma^{2} / 2\right)
\end{aligned}
$$

where the function $\Phi_{\mathrm{FSTS}}(\mu)$ is defined as follows :

$$
\begin{aligned}
& \Phi_{\mathrm{FSTS}}(\mu)= \\
& \sum_{n_{1}=-\infty}^{\infty} \sum_{n_{2}=-\infty}^{\infty}\left(\frac{U_{1}^{n_{1}} U_{2}^{n_{2}}}{D_{1}^{n_{1}} D_{2}^{n_{2}}}\right)^{\frac{2 \mu}{\sigma^{2}}} \\
& \left\{\begin{array}{l}
N_{3}\left[\mathrm{I}_{1}\left(U_{1}\right), \mathrm{I}_{2}\left(U_{1} \wedge U_{2}\right), \mathrm{I}_{3}(K) ; \mathrm{H}_{1}\right]-N_{3}\left[\mathrm{I}_{1}\left(U_{1}\right), \mathrm{I}_{2}\left(U_{1} \wedge U_{2}\right), \mathrm{I}_{3}\left(D_{2}\right) ; \mathrm{H}_{1}\right] \\
-N_{3}\left[\mathrm{I}_{1}\left(U_{1}\right), \mathrm{I}_{2}\left(D_{1} \vee D_{2}\right), \mathrm{I}_{3}(K) ; \mathrm{H}_{1}\right]+N_{3}\left[\mathrm{I}_{1}\left(U_{1}\right), \mathrm{I}_{2}\left(D_{1} \vee D_{2}\right), \mathrm{I}_{3}\left(D_{2}\right) ; \mathrm{H}_{1}\right] \\
-N_{3}\left[\mathrm{I}_{1}\left(D_{1}\right), \mathrm{I}_{2}\left(U_{1} \wedge U_{2}\right), \mathrm{I}_{3}(K) ; \mathrm{H}_{1}\right]+N_{3}\left[\mathrm{I}_{1}\left(D_{1}\right), \mathrm{I}_{2}\left(U_{1} \wedge U_{2}\right), \mathrm{I}_{3}\left(D_{2}\right) ; \mathrm{H}_{1}\right] \\
+N_{3}\left[\mathrm{I}_{1}\left(D_{1}\right), \mathrm{I}_{2}\left(D_{1} \vee D_{2}\right), \mathrm{I}_{3}(K) ; \mathrm{H}_{1}\right]-N_{3}\left[\mathrm{I}_{1}\left(D_{1}\right), \mathrm{I}_{2}\left(D_{1} \vee D_{2}\right), \mathrm{I}_{3}\left(D_{2}\right) ; \mathrm{H}_{1}\right]
\end{array}\right\} \\
& -\sum_{n_{1}=-\infty}^{\infty} \sum_{n_{2}=-\infty}^{\infty}\left(\frac{D_{1}^{n_{1}} D_{2}^{n_{2}+1}}{S_{0} U_{1}^{n_{1}} U_{2}^{n_{2}}}\right)^{\frac{2 \mu}{\sigma^{2}}} \\
& \left\{\begin{array}{l}
-\Phi_{2}\left\{N_{3}\left[\mathrm{I}_{4}\left(U_{1}\right), \mathrm{I}_{5}\left(U_{1} \wedge U_{2}\right), \mathrm{I}_{6}(K) ; \mathrm{H}_{2}\right]-N_{3}\left[\mathrm{I}_{4}\left(U_{1}\right), \mathrm{I}_{5}\left(U_{1} \wedge U_{2}\right), \mathrm{I}_{6}\left(D_{2}\right) ; \mathrm{H}_{2}\right]\right. \\
-N_{3}\left[\mathrm{I}_{4}\left(U_{1}\right), \mathrm{I}_{5}\left(D_{1} \vee D_{2}\right), \mathrm{I}_{6}(K) ; \mathrm{H}_{2}\right]+N_{3}\left[\mathrm{I}_{4}\left(U_{1}\right), \mathrm{I}_{5}\left(D_{1} \vee D_{2}\right), \mathrm{I}_{6}\left(D_{2}\right) ; \mathrm{H}_{2}\right] \\
-N_{3}\left[\mathrm{I}_{4}\left(D_{1}\right), \mathrm{I}_{5}\left(U_{1} \wedge U_{2}\right), \mathrm{I}_{6}(K) ; \mathrm{H}_{2}\right]+N_{3}\left[\mathrm{I}_{4}\left(D_{1}\right), \mathrm{I}_{5}\left(U_{1} \wedge U_{2}\right), \mathrm{I}_{6}\left(D_{2}\right) ; \mathrm{H}_{2}\right] \\
+N_{3}\left[\mathrm{I}_{4}\left(D_{1}\right), \mathrm{I}_{5}\left(D_{1} \vee D_{2}\right), \mathrm{I}_{6}(K) ; \mathrm{H}_{2}\right]-N_{3}\left[\mathrm{I}_{4}\left(D_{1}\right), \mathrm{I}_{5}\left(D_{1} \vee D_{2}\right), \mathrm{I}_{6}\left(D_{2}\right) ; \mathrm{H}_{2}\right]
\end{array}\right\} \\
& -\sum_{n_{1}=-\infty}^{\infty} \sum_{n_{2}=-\infty}^{\infty}\left(\frac{D_{1}^{n_{1}+1} U_{2}^{n_{2}}}{S_{0} U_{1}^{n_{1}} D_{2}^{n_{2}}}\right)^{\frac{2 \mu}{\sigma^{2}}}
\end{aligned}
$$$$
\begin{aligned}
& \left\{\begin{array}{l}
-\Phi_{3}\left\{N_{3}\left[\mathrm{I}_{4}\left(U_{1}\right), \mathrm{I}_{7}\left(U_{1} \wedge U_{2}\right), \mathrm{I}_{8}(K) ; \mathrm{H}_{3}\right]-N_{3}\left[\mathrm{I}_{4}\left(U_{1}\right), \mathrm{I}_{7}\left(U_{1} \wedge U_{2}\right), \mathrm{I}_{8}\left(D_{2}\right) ; \mathrm{H}_{3}\right]\right. \\
-N_{3}\left[\mathrm{I}_{4}\left(U_{1}\right), \mathrm{I}_{7}\left(D_{1} \vee D_{2}\right), \mathrm{I}_{8}(K) ; \mathrm{H}_{3}\right]+N_{3}\left[\mathrm{I}_{4}\left(U_{1}\right), \mathrm{I}_{7}\left(D_{1} \vee D_{2}\right), \mathrm{I}_{8}\left(D_{2}\right) ; \mathrm{H}_{3}\right] \\
-N_{3}\left[\mathrm{I}_{4}\left(D_{1}\right), \mathrm{I}_{7}\left(U_{1} \wedge U_{2}\right), \mathrm{I}_{8}(K) ; \mathrm{H}_{3}\right]+N_{3}\left[\mathrm{I}_{4}\left(D_{1}\right), \mathrm{I}_{7}\left(U_{1} \wedge U_{2}\right), \mathrm{I}_{8}\left(D_{2}\right) ; \mathrm{H}_{3}\right] \\
+N_{3}\left[\mathrm{I}_{4}\left(D_{1}\right), \mathrm{I}_{7}\left(D_{1} \vee D_{2}\right), \mathrm{I}_{8}(K) ; \mathrm{H}_{3}\right]-N_{3}\left[\mathrm{I}_{4}\left(D_{1}\right), \mathrm{I}_{7}\left(D_{1} \vee D_{2}\right), \mathrm{I}_{8}\left(D_{2}\right) ; \mathrm{H}_{3}\right]
\end{array}\right\} \\
& +\sum_{n_{1}=-\infty}^{\infty} \sum_{n_{2}=-\infty}^{\infty}\left(\frac{D_{2}^{n_{2}+1} U_{1}^{n_{1}}}{D_{1}^{n_{1}+1} U_{2}^{n_{2}}}\right)^{\frac{2 \mu}{\sigma^{2}}}
\end{aligned}
$$$$
\left\{\begin{array}{l}
+\Phi_{4}\left\{N_{3}\left[\mathrm{I}_{4}\left(U_{1}\right), \mathrm{I}_{9}\left(U_{1} \wedge U_{2}\right), \mathrm{I}_{10}(K) ; \mathrm{H}_{4}\right]-N_{3}\left[\mathrm{I}_{4}\left(U_{1}\right), \mathrm{I}_{9}\left(U_{1} \wedge U_{2}\right), \mathrm{I}_{10}\left(D_{2}\right) ; \mathrm{H}_{4}\right]\right. \\
-N_{3}\left[\mathrm{I}_{4}\left(U_{1}\right), \mathrm{I}_{9}\left(D_{1} \vee D_{2}\right), \mathrm{I}_{10}(K) ; \mathrm{H}_{4}\right]+N_{3}\left[\mathrm{I}_{4}\left(U_{1}\right), \mathrm{I}_{9}\left(D_{1} \vee D_{2}\right), \mathrm{I}_{10}\left(D_{2}\right) ; \mathrm{H}_{4}\right] \\
-N_{3}\left[\mathrm{I}_{4}\left(D_{1}\right), \mathrm{I}_{9}\left(U_{1} \wedge U_{2}\right), \mathrm{I}_{10}(K) ; \mathrm{H}_{4}\right]+N_{3}\left[\mathrm{I}_{4}\left(D_{1}\right), \mathrm{I}_{9}\left(U_{1} \wedge U_{2}\right), \mathrm{I}_{10}\left(D_{2}\right) ; \mathrm{H}_{4}\right] \\
+N_{3}\left[\mathrm{I}_{4}\left(D_{1}\right), \mathrm{I}_{9}\left(D_{1} \vee D_{2}\right), \mathrm{I}_{10}(K) ; \mathrm{H}_{4}\right]-N_{3}\left[\mathrm{I}_{4}\left(D_{1}\right), \mathrm{I}_{9}\left(D_{1} \vee D_{2}\right), \mathrm{I}_{10}\left(D_{2}\right) ; \mathrm{H}_{4}\right]
\end{array}\right\}
$$ 
where $N_{3}[., ., ., \ldots, .,$.$] is the trivariate standard normal cumulative distribution as defined in$ Proposition 2, and where the remaining functions are given by :

$$
\begin{aligned}
& \mathrm{I}_{1}(X)=\left(\ln \left(\frac{X}{S_{0}}\right)-\mu t_{1}\right) / \sigma \sqrt{t_{1}}, \mathrm{I}_{2}(X)=\left(\ln \left(\frac{X D_{1}^{2 n_{1}}}{S_{0} U_{1}^{2 n_{1}}}\right)-\mu t_{2}\right) / \sigma \sqrt{t_{2}} \\
& \mathrm{I}_{3}(X)=\left(\ln \left(\frac{X D_{2}^{2 n_{2}} D_{1}^{2 n_{1}}}{S_{0} U_{2}^{2 n_{2}} U_{1}^{2 n_{1}}}\right)-\mu t_{3}\right) / \sigma \sqrt{t_{3}}, \mathrm{I}_{4}(X)=\left(\ln \left(\frac{X}{S_{0}}\right)+\mu t_{1}\right) / \sigma \sqrt{t_{1}} \\
& \mathrm{I}_{5}(X)=\left(\ln \left(\frac{X D_{1}^{2 n_{1}}}{S_{0} U_{1}^{2 n_{1}}}\right)+\mu t_{2}\right) / \sigma \sqrt{t_{2}}, \mathrm{I}_{6}(X)=\left(\ln \left(\frac{X S_{0} U_{2}^{2 n_{2}} U_{1}^{2 n_{1}}}{D_{2}^{2\left(n_{2}+1\right)} D_{1}^{2 n_{1}}}\right)-\mu t_{3}\right) / \sigma \sqrt{t_{3}} \\
& \mathrm{I}_{7}(X)=\left(\ln \left(\frac{X S_{0} U_{1}^{2 n_{1}}}{D_{1}^{2\left(n_{1}+1\right)}}\right)-\mu t_{2}\right) / \sigma \sqrt{t_{2}}, \mathrm{I}_{8}(X)=\left(\ln \left(\frac{X S_{0} D_{2}^{2 n_{2}} U_{1}^{2 n_{1}}}{D_{1}^{2\left(n_{1}+1\right)} U_{2}^{2 n_{2}}}\right)-\mu t_{3}\right) / \sigma \sqrt{t_{3}} \\
& \mathrm{I}_{9}(X)=\left(\ln \left(\frac{X S_{0} U_{1}^{2 n_{1}}}{D_{1}^{2\left(n_{1}+1\right)}}\right)+\mu t_{2}\right) / \sigma \sqrt{t_{2}}, \mathrm{I}_{10}(X)=\left(\ln \left(\frac{X D_{1}^{2\left(n_{1}+1\right)} U_{2}^{2 n_{2}}}{S_{0} D_{2}^{2\left(n_{2}+1\right)} U_{1}^{2 n_{1}}}\right)-\mu t_{3}\right) / \sigma \sqrt{t_{3}} \\
& \mathrm{H}_{1}=\left\{\sqrt{\frac{t_{1}}{t_{2}}}, \sqrt{\frac{t_{1}}{t_{3}}}, \sqrt{\frac{t_{2}}{t_{3}}}\right\}, \mathrm{H}_{2}=\left\{\sqrt{\frac{t_{1}}{t_{2}}},-\sqrt{\frac{t_{1}}{t_{3}}},-\sqrt{\frac{t_{2}}{t_{3}}}\right\} \\
& \mathrm{H}_{3}=\left\{-\sqrt{\frac{t_{1}}{t_{2}}},-\sqrt{\frac{t_{1}}{t_{3}}}, \sqrt{\frac{t_{2}}{t_{3}}}\right\}, \mathrm{H}_{4}=\left\{-\sqrt{\frac{t_{1}}{t_{2}}}, \sqrt{\frac{t_{1}}{t_{3}}},-\sqrt{\frac{t_{2}}{t_{3}}}\right\}
\end{aligned}
$$

The numerical implementation of Proposition 3 is easy, as explained right after Proposition 2.

The value of a forward-start two-step double knock-out call, FSTSDKOC, is obtained as follows :

$$
\begin{aligned}
& F \operatorname{FSDKOC}\left(S_{0}, \sigma, r, \delta, t_{1}, t_{2}, t_{3}, K, U_{1}, U_{2}, D_{1}, D_{2}\right) \\
& =\operatorname{FSTSDKOP}\left(S_{0}, \sigma, r, \delta, t_{1}, t_{2}, t_{3}, U_{2}, U_{1}, U_{2}, D_{1}, D_{2}\right) \\
& -\operatorname{FSTSDKOP}\left(S_{0}, \sigma, r, \delta, t_{1}, t_{2}, t_{3}, K, U_{1}, U_{2}, D_{1}, D_{2}\right)
\end{aligned}
$$

The next proposition states the no-arbitrage value of a window two-step double knock-out put as defined in Section 2.

\section{Proposition 4}

The no-arbitrage value of a window two-step double knock-out put (WTSDKOP) is given by:

$$
\begin{aligned}
& \operatorname{WTSDKOP}\left(S_{0}, \sigma, r, \delta, t_{1}, t_{2}, t_{3}, t_{4}, K, U_{1}, U_{2}, D_{1}, D_{2}\right) \\
& =\exp \left(-r t_{4}\right) K \Phi_{\mathrm{WTS}}\left(\mu=r-\delta-\sigma^{2} / 2\right)-\exp \left(-\delta t_{4}\right) S_{0} \Phi_{\mathrm{WTS}}\left(\mu=r-\delta+\sigma^{2} / 2\right)
\end{aligned}
$$

where the function $\Phi_{\mathrm{WTS}}(\mu)$ is defined as follows :

$$
\begin{aligned}
& \Phi_{\mathrm{WTS}}(\mu) \\
& =\sum_{n_{1}=-\infty}^{\infty} \sum_{n_{2}=-\infty}^{\infty}\left(\frac{U_{1}^{n_{1}} U_{2}^{n_{2}}}{D_{1}^{n_{1}} D_{2}^{n_{2}}}\right)^{\frac{2 \mu}{\sigma^{2}}}
\end{aligned}
$$




$$
\begin{aligned}
& N_{4}\left[\mathrm{I}_{1}\left(U_{1}\right), \mathrm{I}_{2}\left(U_{1} \wedge U_{2}\right), \mathrm{I}_{3}\left(U_{2}\right), \mathrm{I}_{4}(K) ; \mathrm{H}_{1}\right]-N_{4}\left[\mathrm{I}_{1}\left(U_{1}\right), \mathrm{I}_{2}\left(U_{1} \wedge U_{2}\right), \mathrm{I}_{3}\left(D_{2}\right), \mathrm{I}_{4}(K) ; \mathrm{H}_{1}\right] \\
& -N_{4}\left[\mathrm{I}_{1}\left(U_{1}\right), \mathrm{I}_{2}\left(D_{1} \vee D_{2}\right), \mathrm{I}_{3}\left(U_{2}\right), \mathrm{I}_{4}(K) ; \mathrm{H}_{1}\right]+N_{4}\left[\mathrm{I}_{1}\left(U_{1}\right), \mathrm{I}_{2}\left(D_{1} \vee D_{2}\right), \mathrm{I}_{3}\left(D_{2}\right), \mathrm{I}_{4}(K) ; \mathrm{H}_{1}\right] \\
& -N_{4}\left[\mathrm{I}_{1}\left(D_{1}\right), \mathrm{I}_{2}\left(U_{1} \wedge U_{2}\right), \mathrm{I}_{3}\left(U_{2}\right), \mathrm{I}_{4}(K) ; \mathrm{H}_{1}\right]+N_{4}\left[\mathrm{I}_{1}\left(D_{1}\right), \mathrm{I}_{2}\left(U_{1} \wedge U_{2}\right), \mathrm{I}_{3}\left(D_{2}\right), \mathrm{I}_{4}(K) ; \mathrm{H}_{1}\right] \\
& \left.+N_{4}\left[\mathrm{I}_{1}\left(D_{1}\right), \mathrm{I}_{2}\left(D_{1} \vee D_{2}\right), \mathrm{I}_{3}\left(U_{2}\right), \mathrm{I}_{4}(K) ; \mathrm{H}_{1}\right]-N_{3}\left[\mathrm{I}_{1}\left(D_{1}\right), \mathrm{I}_{2}\left(D_{1} \vee D_{2}\right), \mathrm{I}_{3}\left(D_{2}\right), \mathrm{I}_{4}(K) ; \mathrm{H}_{1}\right]\right] \\
& -\sum_{n_{1}=-\infty}^{\infty} \sum_{n_{2}=-\infty}^{\infty}\left(\frac{D_{1}^{n_{1}} D_{2}^{n_{2}+1}}{S_{0} U_{1}^{n_{1}} U_{2}^{n_{2}}}\right)^{\frac{2 \mu}{\sigma^{2}}} \\
& \left\{\begin{array}{l}
N_{4}\left[\mathrm{I}_{5}\left(U_{1}\right), \mathrm{I}_{6}\left(U_{1} \wedge U_{2}\right), \mathrm{I}_{7}\left(U_{2}\right), \mathrm{I}_{8}(K) ; \mathrm{H}_{2}\right]-N_{4}\left[\mathrm{I}_{5}\left(U_{1}\right), \mathrm{I}_{6}\left(U_{1} \wedge U_{2}\right), \mathrm{I}_{7}\left(D_{2}\right), \mathrm{I}_{8}(K) ; \mathrm{H}_{2}\right] \\
-N_{4}\left[\mathrm{I}_{5}\left(U_{1}\right), \mathrm{I}_{6}\left(D_{1} \vee D_{2}\right), \mathrm{I}_{7}\left(U_{2}\right), \mathrm{I}_{8}(K) ; \mathrm{H}_{2}\right]+N_{4}\left[\mathrm{I}_{5}\left(U_{1}\right), \mathrm{I}_{6}\left(D_{1} \vee D_{2}\right), \mathrm{I}_{7}\left(D_{2}\right), \mathrm{I}_{8}(K) ; \mathrm{H}_{2}\right] \\
-N_{4}\left[\mathrm{I}_{5}\left(D_{1}\right), \mathrm{I}_{6}\left(U_{1} \wedge U_{2}\right), \mathrm{I}_{7}\left(U_{2}\right), \mathrm{I}_{8}(K) ; \mathrm{H}_{2}\right]+N_{4}\left[\mathrm{I}_{5}\left(D_{1}\right), \mathrm{I}_{6}\left(U_{1} \wedge U_{2}\right), \mathrm{I}_{7}\left(D_{2}\right), \mathrm{I}_{8}(K) ; \mathrm{H}_{2}\right] \\
+N_{4}\left[\mathrm{I}_{5}\left(D_{1}\right), \mathrm{I}_{6}\left(D_{1} \vee D_{2}\right), \mathrm{I}_{7}\left(U_{2}\right), \mathrm{I}_{8}(K) ; \mathrm{H}_{2}\right]-N_{4}\left[\mathrm{I}_{5}\left(D_{1}\right), \mathrm{I}_{6}\left(D_{1} \vee D_{2}\right), \mathrm{I}_{7}\left(D_{2}\right), \mathrm{I}_{8}(K) ; \mathrm{H}_{2}\right]
\end{array}\right\} \\
& -\sum_{n_{1}=-\infty}^{\infty} \sum_{n_{2}=-\infty}^{\infty}\left(\frac{D_{1}^{n_{1}+1} U_{2}^{n_{2}}}{S_{0} U_{1}^{n_{1}} D_{2}^{n_{2}}}\right)^{\frac{2 \mu}{\sigma^{2}}} \\
& \left\{\begin{array}{l}
N_{4}\left[\mathrm{I}_{5}\left(U_{1}\right), \mathrm{I}_{9}\left(U_{1} \wedge U_{2}\right), \mathrm{I}_{10}\left(U_{2}\right), \mathrm{I}_{11}(K) ; \mathrm{H}_{3}\right]-N_{4}\left[\mathrm{I}_{5}\left(U_{1}\right), \mathrm{I}_{9}\left(U_{1} \wedge U_{2}\right), \mathrm{I}_{10}\left(D_{2}\right), \mathrm{I}_{11}(K) ; \mathrm{H}_{3}\right] \\
-N_{4}\left[\mathrm{I}_{5}\left(U_{1}\right), \mathrm{I}_{9}\left(D_{1} \vee D_{2}\right), \mathrm{I}_{10}\left(U_{2}\right), \mathrm{I}_{11}(K) ; \mathrm{H}_{3}\right]+N_{4}\left[\mathrm{I}_{5}\left(U_{1}\right), \mathrm{I}_{9}\left(D_{1} \vee D_{2}\right), \mathrm{I}_{10}\left(D_{2}\right), \mathrm{I}_{11}(K) ; \mathrm{H}_{3}\right] \\
-N_{4}\left[\mathrm{I}_{5}\left(D_{1}\right), \mathrm{I}_{9}\left(U_{1} \wedge U_{2}\right), \mathrm{I}_{10}\left(U_{2}\right), \mathrm{I}_{11}(K) ; \mathrm{H}_{3}\right]+N_{4}\left[\mathrm{I}_{5}\left(D_{1}\right), \mathrm{I}_{9}\left(U_{1} \wedge U_{2}\right), \mathrm{I}_{10}\left(D_{2}\right), \mathrm{I}_{11}(K) ; \mathrm{H}_{3}\right] \\
+N_{4}\left[\mathrm{I}_{5}\left(D_{1}\right), \mathrm{I}_{9}\left(D_{1} \vee D_{2}\right), \mathrm{I}_{10}\left(U_{2}\right), \mathrm{I}_{11}(K) ; \mathrm{H}_{3}\right]-N_{4}\left[\mathrm{I}_{5}\left(D_{1}\right), \mathrm{I}_{9}\left(D_{1} \vee D_{2}\right), \mathrm{I}_{10}\left(D_{2}\right), \mathrm{I}_{11}(K) ; \mathrm{H}_{3}\right]
\end{array}\right\} \\
& +\sum_{n_{1}=-\infty}^{\infty} \sum_{n_{2}=-\infty}^{\infty}\left(\frac{D_{2}^{n_{2}+1} U_{1}^{n_{1}}}{D_{1}^{n_{1}+1} U_{2}^{n_{2}}}\right)^{\frac{2 \mu}{\sigma^{2}}} \\
& \left\{\begin{array}{l}
N_{4}\left[\mathrm{I}_{5}\left(U_{1}\right), \mathrm{I}_{12}\left(U_{1} \wedge U_{2}\right), \mathrm{I}_{13}\left(U_{2}\right), \mathrm{I}_{14}(K) ; \mathrm{H}_{4}\right]-N_{4}\left[\mathrm{I}_{5}\left(U_{1}\right), \mathrm{I}_{12}\left(U_{1} \wedge U_{2}\right), \mathrm{I}_{13}\left(D_{2}\right), \mathrm{I}_{14}(K) ; \mathrm{H}_{4}\right] \\
-N_{4}\left[\mathrm{I}_{5}\left(U_{1}\right), \mathrm{I}_{12}\left(D_{1} \vee D_{2}\right), \mathrm{I}_{13}\left(U_{2}\right), \mathrm{I}_{14}(K) ; \mathrm{H}_{4}\right]+N_{4}\left[\mathrm{I}_{5}\left(U_{1}\right), \mathrm{I}_{12}\left(D_{1} \vee D_{2}\right), \mathrm{I}_{13}\left(D_{2}\right), \mathrm{I}_{14}(K) ; \mathrm{H}_{4}\right] \\
-N_{4}\left[\mathrm{I}_{5}\left(D_{1}\right), \mathrm{I}_{12}\left(U_{1} \wedge U_{2}\right), \mathrm{I}_{13}\left(U_{2}\right), \mathrm{I}_{14}(K) ; \mathrm{H}_{4}\right]+N_{4}\left[\mathrm{I}_{5}\left(D_{1}\right), \mathrm{I}_{12}\left(U_{1} \wedge U_{2}\right), \mathrm{I}_{13}\left(D_{2}\right), \mathrm{I}_{14}(K) ; \mathrm{H}_{4}\right] \\
+N_{4}\left[\mathrm{I}_{5}\left(D_{1}\right), \mathrm{I}_{12}\left(D_{1} \vee D_{2}\right), \mathrm{I}_{13}\left(U_{2}\right), \mathrm{I}_{14}(K) ; \mathrm{H}_{4}\right]-N_{4}\left[\mathrm{I}_{5}\left(D_{1}\right), \mathrm{I}_{12}\left(D_{1} \vee D_{2}\right), \mathrm{I}_{13}\left(D_{2}\right), \mathrm{I}_{14}(K) ; \mathrm{H}_{4}\right]
\end{array}\right\}
\end{aligned}
$$

where $N_{4}\left[b_{1}, b_{2}, b_{3}, b_{4} ; \theta_{12}, \theta_{23}, \theta_{34}\right]$ is a special form of the quadrivariate standard normal cumulative distribution function defined by the following double integral :

$$
\begin{aligned}
& N_{4}\left[b_{1}, b_{2}, b_{3}, b_{4} ; \theta_{12}, \theta_{23}, \theta_{34}\right] \\
& =\int_{-\infty}^{b_{2}} \int_{-\infty}^{b_{3}} \frac{\exp \left(-\frac{x_{2}^{2}}{2}-\frac{1}{2\left(1-\theta_{23}^{2}\right)}\left(x_{3}-\theta_{23} x_{2}\right)^{2}\right)}{2 \pi \sqrt{1-\theta_{23}^{2}}} N\left[\frac{b_{1}-\theta_{12} x_{2}}{\sqrt{1-\theta_{12}^{2}}}\right] N\left[\frac{b_{4}-\theta_{34} x_{3}}{\sqrt{1-\theta_{34}^{2}}}\right] d x_{2} d x_{3}
\end{aligned}
$$

with $N$ [.] being the univariate standard normal cumulative distribution function

The remaining functions are given by:

$$
\mathrm{I}_{1}(X)=\left(\ln \left(\frac{X}{S_{0}}\right)-\mu t_{1}\right) / \sigma \sqrt{t_{1}}, \mathrm{I}_{2}(X)=\left(\ln \left(\frac{X D_{1}^{2 n_{1}}}{S_{0} U_{1}^{2 n_{1}}}\right)-\mu t_{2}\right) / \sigma \sqrt{t_{2}}
$$




$$
\begin{aligned}
& \mathrm{I}_{3}(X)=\left(\ln \left(\frac{X D_{2}^{2 n_{2}} D_{1}^{2 n_{1}}}{S_{0} U_{2}^{2 n_{2}} U_{1}^{2 n_{1}}}\right)-\mu t_{3}\right) / \sigma \sqrt{t_{3}}, \mathrm{I}_{4}(X)=\left(\ln \left(\frac{X D_{2}^{2 n_{2}} D_{1}^{2 n_{1}}}{S_{0} U_{2}^{2 n_{2}} U_{1}^{2 n_{1}}}\right)-\mu t_{4}\right) / \sigma \sqrt{t_{4}} \\
& \mathrm{I}_{5}(X)=\left(\ln \left(\frac{X}{S_{0}}\right)+\mu t_{1}\right) / \sigma \sqrt{t_{1}}, \mathrm{I}_{6}(X)=\left(\ln \left(\frac{X D_{1}^{2 n_{1}}}{S_{0} U_{1}^{2 n_{1}}}\right)+\mu t_{2}\right) / \sigma \sqrt{t_{2}} \\
& \mathrm{I}_{7}(X)=\left(\ln \left(\frac{X S_{0} U_{2}^{2 n_{2}} U_{1}^{2 n_{1}}}{D_{2}^{2\left(n_{2}+1\right)} D_{1}^{2 n_{1}}}\right)-\mu t_{3}\right) / \sigma \sqrt{t_{3}}, \mathrm{I}_{8}(X)=\left(\ln \left(\frac{X S_{0} U_{2}^{2 n_{2}} U_{1}^{2 n_{1}}}{D_{2}^{2\left(n_{2}+1\right)} D_{1}^{2 n_{1}}}\right)-\mu t_{4}\right) / \sigma \sqrt{t_{4}} \\
& \mathrm{I}_{9}(X)=\left(\ln \left(\frac{X S_{0} U_{1}^{2 n_{1}}}{D_{1}^{2\left(n_{1}+1\right)}}\right)-\mu t_{2}\right) / \sigma \sqrt{t_{2}}, \mathrm{I}_{10}(X)=\left(\ln \left(\frac{X S_{0} D_{2}^{2 n_{2}} U_{1}^{2 n_{1}}}{D_{1}^{2\left(n_{1}+1\right)} U_{2}^{2 n_{2}}}\right)-\mu t_{3}\right) / \sigma \sqrt{t_{3}} \\
& \mathrm{I}_{11}(X)=\left(\ln \left(\frac{X S_{0} D_{2}^{2 n_{2}} U_{1}^{2 n_{1}}}{D_{1}^{2\left(n_{1}+1\right)} U_{2}^{2 n_{2}}}\right)-\mu t_{4}\right) / \sigma \sqrt{t_{4}}, \mathrm{I}_{12}(X)=\left(\ln \left(\frac{X S_{0} U_{1}^{2 n_{1}}}{D_{1}^{2\left(n_{1}+1\right)}}\right)+\mu t_{2}\right) / \sigma \sqrt{t_{2}} \\
& \mathrm{I}_{13}(X)=\left(\ln \left(\frac{X D_{1}^{2\left(n_{1}+1\right)} U_{2}^{2 n_{2}}}{S_{0} D_{2}^{2\left(n_{2}+1\right)} U_{1}^{2 n_{1}}}\right)-\mu t_{3}\right) / \sigma \sqrt{t_{3}}, \mathrm{I}_{14}(X)=\left(\ln \left(\frac{X D_{1}^{2\left(n_{1}+1\right)} U_{2}^{2 n_{2}}}{S_{0} D_{2}^{2\left(n_{2}+1\right)} U_{1}^{2 n_{1}}}\right)-\mu t_{4}\right) / \sigma \sqrt{t_{4}} \\
& \mathrm{H}_{1}=\left\{\sqrt{\frac{t_{1}}{t_{2}}}, \sqrt{\frac{t_{2}}{t_{3}}}, \sqrt{\frac{t_{3}}{t_{4}}}\right\}, \mathrm{H}_{2}=\left\{\sqrt{\frac{t_{1}}{t_{2}}},-\sqrt{\frac{t_{2}}{t_{3}}}, \sqrt{\frac{t_{3}}{t_{4}}}\right\} \\
& \mathrm{H}_{3}=\left\{-\sqrt{\frac{t_{1}}{t_{2}}}, \sqrt{\frac{t_{2}}{t_{3}}}, \sqrt{\frac{t_{3}}{t_{4}}}\right\}, \mathrm{H}_{4}=\left\{-\sqrt{\frac{t_{1}}{t_{2}}},-\sqrt{\frac{t_{2}}{t_{3}}}, \sqrt{\frac{t_{3}}{t_{4}}}\right\}
\end{aligned}
$$

The numerical implementation of Proposition 4 requires a quadrature rule to compute the $N_{4}$ [.] functions. It is therefore less straightforward than the implementation of the other formulae in this appendix. Given the low dimension and the smoothness of the integrand, one can use a classical Gauss-Legendre rule. However, extensive testing shows that numerical inaccuracies may arise for large values of $n_{1}$ and $n_{2}$, so that it is questionable to use Proposition 4 without a sufficiently robust numerical integration routine. It must be stressed that, of all the seven formulae provided in this appendix, Proposition 4 is the only one to raise potential numerical issues.

The value of a window two-step double knock-out call, WTSDKOC, is obtained as follows :

$$
\begin{aligned}
& \operatorname{WTSDKOC}\left(S_{0}, \sigma, r, \delta, t_{1}, t_{2}, t_{3}, t_{4}, K, U_{1}, U_{2}, D_{1}, D_{2}\right) \\
& =\operatorname{WTSDKOP}\left(S_{0}, \sigma, r, \delta, t_{1}, t_{2}, t_{3}, t_{4}, A, U_{1}, U_{2}, D_{1}, D_{2}\right) \\
& -W T S D K O P\left(S_{0}, \sigma, r, \delta, t_{1}, t_{2}, t_{3}, t_{4}, K, U_{1}, U_{2}, D_{1}, D_{2}\right)
\end{aligned}
$$

where $A$ is « large » (as explained in Proposition 2).

The next proposition states the no-arbitrage value of an outside two-step double knock-out put as defined in Section 3. 


\section{Proposition 5}

The no-arbitrage value of an outside two-step double knock-out put (OTSDKOP) is given by:

$$
\begin{aligned}
& \operatorname{OTSDKOP}\left(S_{0}^{(1)}, S_{0}^{(2)}, \sigma_{1}, \sigma_{2}, r, \delta_{1}, \delta_{2}, t_{1}, t_{2}, K, U_{1}, U_{2}, D_{1}, D_{2}\right) \\
& =\exp \left(-r t_{2}\right) K \Phi_{\text {OTS }}\left(\mu_{1}=r-\delta_{1}-\sigma_{1}^{2} / 2, \mu_{2}=r-\delta_{2}-\sigma_{2}^{2} / 2\right) \\
& -\exp \left(-\delta_{2} t_{2}\right) S_{0}^{(2)} \Phi_{\mathrm{OTS}}\left(\mu_{1}=r-\delta_{1}+\sigma_{1} \sigma_{2} \rho_{12}-\sigma_{1}^{2} / 2, \mu_{2}=r-\delta_{2}+\sigma_{2}^{2} / 2\right)
\end{aligned}
$$

where the function $\Phi_{\text {OTS }}(\mu)$ is defined as follows :

$$
\begin{aligned}
& \Phi_{\text {OTS }}(\mu)= \\
& \sum_{n_{1}=-\infty}^{\infty} \sum_{n_{2}=-\infty}^{\infty}\left(\frac{U_{1}^{n_{1}} U_{2}^{n_{2}}}{D_{1}^{n_{1}} D_{2}^{n_{2}}}\right)^{\frac{2 \mu_{1}}{\sigma_{1}^{2}}} \\
& \left\{\begin{array}{l}
N_{3}\left[\mathrm{I}_{1}\left(U_{1} \wedge U_{2}\right), \mathrm{I}_{2}\left(U_{2}\right), \mathrm{I}_{3}(K) ; \mathrm{H}_{1}\right]-N_{3}\left[\mathrm{I}_{1}\left(D_{1} \vee D_{2}\right), \mathrm{I}_{2}\left(U_{2}\right), \mathrm{I}_{3}(K) ; \mathrm{H}_{1}\right] \\
\left.-N_{3}\left[\mathrm{I}_{1}\left(U_{1} \wedge U_{2}\right), \mathrm{I}_{2}\left(D_{2}\right), \mathrm{I}_{3}(K) ; \mathrm{H}_{1}\right]+N_{3}\left[\mathrm{I}_{1}\left(D_{1} \vee D_{2}\right), \mathrm{I}_{2}\left(D_{2}\right), \mathrm{I}_{3}(K) ; \mathrm{H}_{1}\right]\right\}
\end{array}\right. \\
& -\sum_{n_{1}=-\infty}^{\infty} \sum_{n_{2}=-\infty}^{\infty}\left(\frac{D_{2}^{n_{2}+1} D_{1}^{n_{1}}}{S_{0}^{(1)} U_{1}^{n_{1}} U_{2}^{n_{2}}}\right)^{\frac{2 \mu_{1}}{\sigma_{1}^{2}}} \\
& \left\{\begin{array}{l}
N_{3}\left[\mathrm{I}_{4}\left(U_{1} \wedge U_{2}\right), \mathrm{I}_{5}\left(U_{2}\right), \mathrm{I}_{6}(K) ; \mathrm{H}_{2}\right]-N_{3}\left[\mathrm{I}_{4}\left(D_{1} \vee D_{2}\right), \mathrm{I}_{5}\left(U_{2}\right), \mathrm{I}_{6}(K) ; \mathrm{H}_{2}\right] \\
\left.-N_{3}\left[\mathrm{I}_{4}\left(U_{1} \wedge U_{2}\right), \mathrm{I}_{5}\left(D_{2}\right), \mathrm{I}_{6}(K) ; \mathrm{H}_{2}\right]+N_{3}\left[\mathrm{I}_{4}\left(D_{1} \vee D_{2}\right), \mathrm{I}_{5}\left(D_{2}\right), \mathrm{I}_{6}(K) ; \mathrm{H}_{2}\right]\right]
\end{array}\right. \\
& -\sum_{n_{1}=-\infty}^{\infty} \sum_{n_{2}=-\infty}^{\infty}\left(\frac{D_{1}^{n_{1}+1} U_{2}^{n_{2}}}{S_{0}^{(1)} U_{1}^{n_{1}} D_{2}^{n_{2}}}\right)^{\frac{2 \mu_{1}}{\sigma_{1}^{2}}} \\
& \left\{\begin{array}{l}
N_{3}\left[\mathrm{I}_{7}\left(U_{1} \wedge U_{2}\right), \mathrm{I}_{8}\left(U_{2}\right), \mathrm{I}_{9}(K) ; \mathrm{H}_{1}\right]-N_{3}\left[\mathrm{I}_{7}\left(D_{1} \vee D_{2}\right), \mathrm{I}_{8}\left(U_{2}\right), \mathrm{I}_{9}(K) ; \mathrm{H}_{1}\right] \\
-N_{3}\left[\mathrm{I}_{7}\left(U_{1} \wedge U_{2}\right), \mathrm{I}_{8}\left(D_{2}\right), \mathrm{I}_{9}(K) ; \mathrm{H}_{1}\right]+N_{3}\left[\mathrm{I}_{7}\left(D_{1} \vee D_{2}\right), \mathrm{I}_{8}\left(D_{2}\right), \mathrm{I}_{9}(K) ; \mathrm{H}_{1}\right]
\end{array}\right\} \\
& +\sum_{n_{1}=-\infty}^{\infty} \sum_{n_{2}=-\infty}^{\infty}\left(\frac{U_{1}^{n_{1}} D_{2}^{n_{2}+1}}{D_{1}^{n_{1}+1} U_{2}^{n_{2}}}\right)^{\frac{2 \mu_{1}}{\sigma_{1}^{2}}} \\
& \left\{\begin{array}{l}
N_{3}\left[\mathrm{I}_{10}\left(U_{1} \wedge U_{2}\right), \mathrm{I}_{11}\left(U_{2}\right), \mathrm{I}_{12}(K) ; \mathrm{H}_{2}\right]-N_{3}\left[\mathrm{I}_{10}\left(D_{1} \vee D_{2}\right), \mathrm{I}_{11}\left(U_{2}\right), \mathrm{I}_{12}(K) ; \mathrm{H}_{2}\right] \\
\left.-N_{3}\left[\mathrm{I}_{10}\left(U_{1} \wedge U_{2}\right), \mathrm{I}_{11}\left(D_{2}\right), \mathrm{I}_{12}(K) ; \mathrm{H}_{2}\right]+N_{3}\left[\mathrm{I}_{10}\left(D_{1} \vee D_{2}\right), \mathrm{I}_{11}\left(D_{2}\right), \mathrm{I}_{12}(K) ; \mathrm{H}_{2}\right]\right\}
\end{array}\right.
\end{aligned}
$$

where $N_{3}[., \ldots, ., \ldots, .$.$] is the trivariate standard normal cumulative distribution as defined in$ Proposition 2, and where the remaining functions are given by:

$$
\begin{aligned}
& \mathrm{I}_{1}(X)=\left(\ln \left(\frac{X D_{1}^{2 n_{1}}}{S_{0}^{(1)} U_{1}^{2 n_{1}}}\right)-\mu_{1} t_{1}\right) / \sigma_{1} \sqrt{t_{1}}, \mathrm{I}_{2}(X)=\left(\ln \left(\frac{X D_{2}^{2 n_{2}} D_{1}^{2 n_{1}}}{S_{0}^{(1)} U_{2}^{2 n_{2}} U_{1}^{2 n_{1}}}\right)-\mu_{1} t_{2}\right) / \sigma_{1} \sqrt{t_{2}} \\
& \mathrm{I}_{3}(X)=\left(\ln \left(\frac{X}{S_{0}^{(2)}}\right)-\mu_{2} t_{2}\right) / \sigma_{2} \sqrt{t_{2}}+\ln \left(\frac{D_{2}^{2 \rho n_{2}} D_{1}^{2 \rho n_{1}}}{U_{2}^{2 \rho n_{2}} U_{1}^{2 \rho n_{1}}}\right) / \sigma_{1} \sqrt{t_{2}} \\
& \mathrm{I}_{4}(X)=\left(\ln \left(\frac{X D_{1}^{2 n_{1}}}{S_{0}^{(1)} U_{1}^{2 n_{1}}}\right)+\mu_{1} t_{1}\right) / \sigma_{1} \sqrt{t_{1}}, \mathrm{I}_{5}(X)=\left(\ln \left(\frac{X S_{0}^{(1)} U_{2}^{2 n_{2}} U_{1}^{2 n_{1}}}{D_{2}^{2\left(n_{2}+1\right)} D_{1}^{2 n_{1}}}\right)-\mu_{1} t_{2}\right) / \sigma_{1} \sqrt{t_{2}}
\end{aligned}
$$




$$
\begin{aligned}
& \mathrm{I}_{6}(X)=\left(\ln \left(\frac{X}{S_{0}^{(2)}}\right)-\mu_{2} t_{2}\right) / \sigma_{2} \sqrt{t_{2}}+\ln \left(\frac{\left(S_{0}^{(1)}\right)^{2 \rho} U_{2}^{2 \rho n_{2}} U_{1}^{2 \rho n_{1}}}{D_{2}^{2 \rho\left(n_{2}+1\right)} D_{1}^{2 \rho n_{1}}}\right) / \sigma_{1} \sqrt{t_{2}} \\
& \mathrm{I}_{7}(X)=\left(\ln \left(\frac{X S_{0}^{(1)} U_{1}^{2 n_{1}}}{D_{1}^{2\left(n_{1}+1\right)}}\right)-\mu_{1} t_{1}\right) / \sigma_{1} \sqrt{t_{1}}, \mathrm{I}_{8}(X)=\left(\ln \left(\frac{X S_{0}^{(1)} D_{2}^{2 n_{2}} U_{1}^{2 n_{1}}}{D_{1}^{2\left(n_{1}+1\right)} U_{2}^{2 n_{2}}}\right)-\mu_{1} t_{2}\right) / \sigma_{1} \sqrt{t_{2}} \\
& \mathrm{I}_{9}(X)=\left(\ln \left(\frac{X}{S_{0}^{(2)}}\right)-\mu_{2} t_{2}\right) / \sigma_{2} \sqrt{t_{2}}+\ln \left(\frac{\left(S_{0}^{(1)}\right)^{2 \rho} D_{2}^{2 \rho n_{2}} U_{1}^{2 \rho n_{1}}}{D_{1}^{2 \rho\left(n_{1}+1\right)} U_{2}^{2 \rho n_{2}}}\right) / \sigma_{1} \sqrt{t_{2}} \\
& \mathrm{I}_{10}(X)=\left(\ln \left(\frac{X S_{0}^{(1)} U_{1}^{2 n_{1}}}{D_{1}^{2\left(n_{1}+1\right)}}\right)+\mu_{1} t_{1}\right) / \sigma_{1} \sqrt{t_{1}}, \mathrm{I}_{11}(X)=\left(\ln \left(\frac{X D_{1}^{2\left(n_{1}+1\right)} U_{2}^{2 n_{2}}}{S_{0}^{(1)} D_{2}^{2\left(n_{2}+1\right)} U_{1}^{2 n_{1}}}\right)-\mu_{1} t_{2}\right) / \sigma_{1} \sqrt{t_{2}} \\
& \mathrm{I}_{12}(X)=\left(\ln \left(\frac{X}{S_{0}^{(2)}}\right)-\mu_{2} t_{2}\right) / \sigma_{2} \sqrt{t_{2}}+\ln \left(\frac{D_{1}^{2 \rho\left(n_{1}+1\right)} U_{2}^{2 \rho n_{2}}}{D_{2}^{2 \rho\left(n_{2}+1\right)} U_{1}^{2 \rho n_{1}}}\right) / \sigma_{1} \sqrt{t_{2}} \\
& \mathrm{H}_{1}=\left\{\sqrt{\frac{t_{1}}{t_{2}}}, \rho \sqrt{\frac{t_{1}}{t_{2}}}, \rho\right\}, \mathrm{H}_{2}=\left\{-\sqrt{\frac{t_{1}}{t_{2}}},-\rho \sqrt{\frac{t_{1}}{t_{2}}}, \rho\right\}
\end{aligned}
$$

The numerical implementation of Proposition 5 is identical to that of Proposition 2. The value of an outside two-step double knock-out call, OTSDKOC, is obtained as follows :

$$
\begin{aligned}
& \operatorname{OTSDKOC}\left(S_{0}^{(1)}, S_{0}^{(2)}, \sigma_{1}, \sigma_{2}, r, \delta_{1}, \delta_{2}, t_{1}, t_{2}, K, U_{1}, U_{2}, D_{1}, D_{2}\right) \\
& =\operatorname{OTSDKOP}\left(S_{0}^{(1)}, S_{0}^{(2)}, \sigma_{1}, \sigma_{2}, r, \delta_{1}, \delta_{2}, t_{1}, t_{2}, A, U_{1}, U_{2}, D_{1}, D_{2}\right) \\
& -\operatorname{OTSDKOP}\left(S_{0}^{(1)}, S_{0}^{(2)}, \sigma_{1}, \sigma_{2}, r, \delta_{1}, \delta_{2}, t_{1}, t_{2}, K, U_{1}, U_{2}, D_{1}, D_{2}\right)
\end{aligned}
$$

where $A$ is « large » (as explained right after Proposition 2).

The next proposition states the no-arbitrage value of an outside early-ending two-step double knockout put, OEETSDKOP, as defined in Section 3.

\section{Proposition 6}

The no-arbitrage value of an outside early-ending two-step double knock-out put (OEETSDKOP) is given by:

$$
\begin{aligned}
& \operatorname{OEETSDKOP}\left(S_{0}^{(1)}, S_{0}^{(2)}, \sigma_{1}, \sigma_{2}, r, \delta_{1}, \delta_{2}, t_{1}, t_{2}, t_{3}, K, U_{1}, U_{2}, D_{1}, D_{2}\right) \\
& =\exp \left(-r t_{3}\right) K \Phi_{\text {OEETS }}\left(\mu_{1}=r-\delta_{1}-\sigma_{1}^{2} / 2, \mu_{2}=r-\delta_{2}-\sigma_{2}^{2} / 2\right) \\
& -\exp \left(-\delta_{2} t_{3}\right) S_{0}^{(2)} \Phi_{\text {OEETS }}\left(\mu_{1}=r-\delta_{1}+\sigma_{1} \sigma_{2} \rho_{12}-\sigma_{1}^{2} / 2, \mu_{2}=r-\delta_{2}+\sigma_{2}^{2} / 2\right)
\end{aligned}
$$

where the function $\Phi_{\text {OEETS }}(\mu)$ defined as follows : 
$\Phi_{\text {OEETS }}(\mu)=$

$\sum_{n_{1}=-\infty}^{\infty} \sum_{n_{2}=-\infty}^{\infty}\left(\frac{U_{1}^{n_{1}} U_{2}^{n_{2}}}{D_{1}^{n_{1}} D_{2}^{n_{2}}}\right)^{\frac{2 \mu_{1}}{\sigma_{1}^{2}}}$

$\left\{\begin{array}{l}N_{3}\left[\mathrm{I}_{1}\left(U_{1} \wedge U_{2}\right), \mathrm{I}_{2}\left(U_{2}\right), \mathrm{I}_{3}(K) ; \mathrm{H}_{1}\right]-N_{3}\left[\mathrm{I}_{1}\left(D_{1} \vee D_{2}\right), \mathrm{I}_{2}\left(U_{2}\right), \mathrm{I}_{3}(K) ; \mathrm{H}_{1}\right] \\ -N_{3}\left[\mathrm{I}_{1}\left(U_{1} \wedge U_{2}\right), \mathrm{I}_{2}\left(D_{2}\right), \mathrm{I}_{3}(K) ; \mathrm{H}_{1}\right]+N_{3}\left[\mathrm{I}_{1}\left(D_{1} \vee D_{2}\right), \mathrm{I}_{2}\left(D_{2}\right), \mathrm{I}_{3}(K) ; \mathrm{H}_{1}\right]\end{array}\right\}$

$-\sum_{n_{1}=-\infty}^{\infty} \sum_{n_{2}=-\infty}^{\infty}\left(\frac{D_{2}^{n_{2}+1} D_{1}^{n_{1}}}{S_{0}^{(1)} U_{1}^{n_{1}} U_{2}^{n_{2}}}\right)^{\frac{2 \mu_{1}}{\sigma_{1}^{2}}}$

$\left\{\begin{array}{l}N_{3}\left[\mathrm{I}_{4}\left(U_{1} \wedge U_{2}\right), \mathrm{I}_{5}\left(U_{2}\right), \mathrm{I}_{6}(K) ; \mathrm{H}_{2}\right]-N_{3}\left[\mathrm{I}_{4}\left(D_{1} \vee D_{2}\right), \mathrm{I}_{5}\left(U_{2}\right), \mathrm{I}_{6}(K) ; \mathrm{H}_{2}\right] \\ -N_{3}\left[\mathrm{I}_{4}\left(U_{1} \wedge U_{2}\right), \mathrm{I}_{5}\left(D_{2}\right), \mathrm{I}_{6}(K) ; \mathrm{H}_{2}\right]+N_{3}\left[\mathrm{I}_{4}\left(D_{1} \vee D_{2}\right), \mathrm{I}_{5}\left(D_{2}\right), \mathrm{I}_{6}(K) ; \mathrm{H}_{2}\right]\end{array}\right\}$

$-\sum_{n_{1}=-\infty}^{\infty} \sum_{n_{2}=-\infty}^{\infty}\left(\frac{D_{1}^{n_{1}+1} U_{2}^{n_{2}}}{S_{0}^{(1)} U_{1}^{n_{1}} D_{2}^{n_{2}}}\right)^{\frac{2 \mu_{1}}{\sigma_{1}^{2}}}$

$\left\{\begin{array}{l}N_{3}\left[\mathrm{I}_{7}\left(U_{1} \wedge U_{2}\right), \mathrm{I}_{8}\left(U_{2}\right), \mathrm{I}_{9}(K) ; \mathrm{H}_{1}\right]-N_{3}\left[\mathrm{I}_{7}\left(D_{1} \vee D_{2}\right), \mathrm{I}_{8}\left(U_{2}\right), \mathrm{I}_{9}(K) ; \mathrm{H}_{1}\right] \\ -N_{3}\left[\mathrm{I}_{7}\left(U_{1} \wedge U_{2}\right), \mathrm{I}_{8}\left(D_{2}\right), \mathrm{I}_{9}(K) ; \mathrm{H}_{1}\right]+N_{3}\left[\mathrm{I}_{7}\left(D_{1} \vee D_{2}\right), \mathrm{I}_{8}\left(D_{2}\right), \mathrm{I}_{9}(K) ; \mathrm{H}_{1}\right]\end{array}\right\}$

$+\sum_{n_{1}=-\infty}^{\infty} \sum_{n_{2}=-\infty}^{\infty}\left(\frac{U_{1}^{n_{1}} D_{2}^{n_{2}+1}}{D_{1}^{n_{1}+1} U_{2}^{n_{2}}}\right)^{\frac{2 \mu_{1}}{\sigma_{1}^{2}}}$

$\left\{\begin{array}{l}N_{3}\left[\mathrm{I}_{10}\left(U_{1} \wedge U_{2}\right), \mathrm{I}_{11}\left(U_{2}\right), \mathrm{I}_{12}(K) ; \mathrm{H}_{2}\right]-N_{3}\left[\mathrm{I}_{10}\left(D_{1} \vee D_{2}\right), \mathrm{I}_{11}\left(U_{2}\right), \mathrm{I}_{12}(K) ; \mathrm{H}_{2}\right] \\ -N_{3}\left[\mathrm{I}_{10}\left(U_{1} \wedge U_{2}\right), \mathrm{I}_{11}\left(D_{2}\right), \mathrm{I}_{12}(K) ; \mathrm{H}_{2}\right]+N_{3}\left[\mathrm{I}_{10}\left(D_{1} \vee D_{2}\right), \mathrm{I}_{11}\left(D_{2}\right), \mathrm{I}_{12}(K) ; \mathrm{H}_{2}\right]\end{array}\right\}$

where $N_{3}[., ., ., \ldots, .,$.$] is the trivariate standard normal cumulative distribution as defined in$ Proposition 2, and where the remaining functions are given by :

$$
\begin{aligned}
& \mathrm{I}_{1}(X)=\left(\ln \left(\frac{X D_{1}^{2 n_{1}}}{S_{0}^{(1)} U_{1}^{2 n_{1}}}\right)-\mu_{1} t_{1}\right) / \sigma_{1} \sqrt{t_{1}}, \mathrm{I}_{2}(X)=\left(\ln \left(\frac{X D_{2}^{2 n_{2}} D_{1}^{2 n_{1}}}{S_{0}^{(1)} U_{2}^{2 n_{2}} U_{1}^{2 n_{1}}}\right)-\mu_{1} t_{2}\right) / \sigma_{1} \sqrt{t_{2}} \\
& \mathrm{I}_{3}(X)=\left(\ln \left(\frac{X}{S_{0}^{(2)}}\right)-\mu_{2} t_{3}\right) / \sigma_{2} \sqrt{t_{3}}+\ln \left(\frac{D_{2}^{2 \rho n_{2}} D_{1}^{2 \rho n_{1}}}{U_{2}^{2 \rho n_{2}} U_{1}^{2 \rho n_{1}}}\right) / \sigma_{1} \sqrt{t_{3}} \\
& \mathrm{I}_{4}(X)=\left(\ln \left(\frac{X D_{1}^{2 n_{1}}}{S_{0}^{(1)} U_{1}^{2 n_{1}}}\right)+\mu_{1} t_{1}\right) / \sigma_{1} \sqrt{t_{1}}, \mathrm{I}_{5}(X)=\left(\ln \left(\frac{X S_{0}^{(1)} U_{2}^{2 n_{2}} U_{1}^{2 n_{1}}}{D_{2}^{2\left(n_{2}+1\right)} D_{1}^{2 n_{1}}}\right)-\mu_{1} t_{2}\right) / \sigma_{1} \sqrt{t_{2}} \\
& \mathrm{I}_{6}(X)=\left(\ln \left(\frac{X}{S_{0}^{(2)}}\right)-\mu_{2} t_{3}\right) / \sigma_{2} \sqrt{t_{3}}+\ln \left(\frac{\left(S_{0}^{(1)}\right)^{2 \rho} U_{2}^{2 \rho n_{2}} U_{1}^{2 \rho n_{1}}}{D_{2}^{2 \rho\left(n_{2}+1\right)} D_{1}^{2 \rho n_{1}}}\right) / \sigma_{1} \sqrt{t_{3}} \\
& \mathrm{I}_{7}(X)=\left(\ln \left(\frac{X S_{0}^{(1)} U_{1}^{2 n_{1}}}{D_{1}^{2\left(n_{1}+1\right)}}\right)-\mu_{1} t_{1}\right) / \sigma_{1} \sqrt{t_{1}}, \mathrm{I}_{8}(X)=\left(\ln \left(\frac{X S_{0}^{(1)} D_{2}^{2 n_{2}} U_{1}^{2 n_{1}}}{D_{1}^{2\left(n_{1}+1\right)} U_{2}^{22 n_{2}}}\right)-\mu_{1} t_{2}\right) / \sigma_{1} \sqrt{t_{2}} \\
& \mathrm{I}_{9}(X)=\left(\ln \left(\frac{X}{S_{0}^{(2)}}\right)-\mu_{2} t_{3}\right) / \sigma_{2} \sqrt{t_{3}}+\ln \left(\frac{\left(S_{0}^{(1)}\right)^{2 \rho} D_{2}^{2 \rho n_{2}} U_{1}^{2 \rho n_{1}}}{D_{1}^{2 \rho\left(n_{1}+1\right)} U_{2}^{2 \rho n_{2}}}\right) / \sigma_{1} \sqrt{t_{3}} \\
& \mathrm{I}_{10}(X)=\left(\ln \left(\frac{X S_{0}^{(1)} U_{1}^{2 n_{1}}}{D_{1}^{2\left(n_{1}+1\right)}}\right)+\mu_{1} t_{1}\right) / \sigma_{1} \sqrt{t_{1}}, \mathrm{I}_{11}(X)=\left(\ln \left(\frac{X D_{1}^{2\left(n_{1}+1\right)} U_{2}^{2 n_{2}}}{S_{0}^{(1)} D_{2}^{2\left(n_{2}+1\right)} U_{1}^{2 n_{1}}}\right)-\mu_{1} t_{2}\right) / \sigma_{1} \sqrt{t_{2}}
\end{aligned}
$$




$$
\begin{aligned}
& \mathrm{I}_{12}(X)=\left(\ln \left(\frac{X}{S_{0}^{(2)}}\right)-\mu_{2} t_{3}\right) / \sigma_{2} \sqrt{t_{3}}+\ln \left(\frac{D_{1}^{2 \rho\left(n_{1}+1\right)} U_{2}^{2 \rho n_{2}}}{D_{2}^{2 \rho\left(n_{2}+1\right)} U_{1}^{2 \rho n_{1}}}\right) / \sigma_{1} \sqrt{t_{3}} \\
& \mathrm{H}_{1}=\left\{\sqrt{\frac{t_{1}}{t_{2}}}, \rho \sqrt{\frac{t_{1}}{t_{3}}}, \rho \sqrt{\frac{t_{2}}{t_{3}}}\right\}, \mathrm{H}_{2}=\left\{-\sqrt{\frac{t_{1}}{t_{2}}},-\rho \sqrt{\frac{t_{1}}{t_{3}}}, \rho \sqrt{\frac{t_{2}}{t_{3}}}\right\}
\end{aligned}
$$

The numerical implementation of Proposition 6 is identical to that of Proposition 2.

The next and final proposition states the no-arbitrage value of a two-asset two-step double knock-out put, TATSDKOP, as defined in Section 3.

\section{Proposition 7}

The no-arbitrage value of a two-asset two-step double knock-out put (TATSDKOP) is given by:

$$
\begin{aligned}
& \operatorname{TATSDKOP}\left(S_{0}^{(1)}, S_{0}^{(2)}, \sigma_{1}, \sigma_{2}, r, \delta_{1}, \delta_{2}, t_{1}, t_{2}, K, U_{1}, U_{2}, D_{1}, D_{2}\right) \\
& =\exp \left(-r t_{2}\right) K \Phi_{\mathrm{TATS}}\left(\mu_{1}=r-\delta_{1}-\sigma_{1}^{2} / 2, \mu_{2}=r-\delta_{2}-\sigma_{2}^{2} / 2\right) \\
& -\exp \left(-\delta_{2} t_{2}\right) S_{0}^{(2)} \Phi_{\mathrm{TATS}}\left(\mu_{1}=r-\delta_{1}+\sigma_{1} \sigma_{2} \rho_{12}-\sigma_{1}^{2} / 2, \mu_{2}=r-\delta_{2}+\sigma_{2}^{2} / 2\right)
\end{aligned}
$$

where the function $\Phi_{\mathrm{TATS}}(\mu)$ is defined as follows :

$$
\begin{aligned}
& \Phi_{\text {TATS }}(\mu)= \\
& \sum_{n_{1}=-\infty}^{\infty} \sum_{n_{2}=-\infty}^{\infty}\left(\frac{U_{1}^{n_{1}}}{D_{1}^{n_{1}}}\right)^{\frac{2 \mu_{1}}{\sigma_{1}^{2}}}\left(\frac{U_{2}^{n_{2}}}{D_{2}^{n_{2}}}\right)^{\frac{2 \mu_{2}}{\sigma_{2}^{2}}} \\
& \left\{\begin{array}{l}
N_{3}\left[\mathrm{I}_{1}\left(U_{1}\right), \mathrm{I}_{2}\left(U_{2}\right), \mathrm{I}_{3}(K) ; \mathrm{H}_{1}\right]-N_{3}\left[\mathrm{I}_{1}\left(D_{1}\right), \mathrm{I}_{2}\left(U_{2}\right), \mathrm{I}_{3}(K) ; \mathrm{H}_{1}\right] \\
-N_{3}\left[\mathrm{I}_{1}\left(U_{1}\right), \mathrm{I}_{2}\left(D_{2}\right), \mathrm{I}_{3}(K) ; \mathrm{H}_{1}\right]+N_{3}\left[\mathrm{I}_{1}\left(D_{1}\right), \mathrm{I}_{2}\left(D_{2}\right), \mathrm{I}_{3}(K) ; \mathrm{H}_{1}\right] \\
-N_{3}\left[\mathrm{I}_{1}\left(U_{1}\right), \mathrm{I}_{2}\left(U_{2}\right), \mathrm{I}_{3}\left(D_{2}\right) ; \mathrm{H}_{1}\right]+N_{3}\left[\mathrm{I}_{1}\left(D_{1}\right), \mathrm{I}_{2}\left(U_{2}\right), \mathrm{I}_{3}\left(D_{2}\right) ; \mathrm{H}_{1}\right] \\
+N_{3}\left[\mathrm{I}_{1}\left(U_{1}\right), \mathrm{I}_{2}\left(D_{2}\right), \mathrm{I}_{3}\left(D_{2}\right) ; \mathrm{H}_{1}\right]-N_{3}\left[\mathrm{I}_{1}\left(D_{1}\right), \mathrm{I}_{2}\left(D_{2}\right), \mathrm{I}_{3}\left(D_{2}\right) ; \mathrm{H}_{1}\right]
\end{array}\right\} \\
& -\sum_{n_{1}=-\infty}^{\infty} \sum_{n_{2}=-\infty}^{\infty}\left(\frac{U_{1}^{n_{1}}}{D_{1}^{n_{1}}}\right)^{\left(\frac{2 \mu_{1}}{\sigma_{1}^{2}}-\frac{4 \rho \mu_{2}}{\sigma_{1} \sigma_{2}}\right)}\left(\frac{D_{2}^{n_{2}+1}}{S_{0}^{(2)} U_{2}^{n_{2}}}\right)^{\frac{2 \mu_{2}}{\sigma_{2}^{2}}} \\
& \left\{\begin{array}{l}
N_{3}\left[\mathrm{I}_{4}\left(U_{1}\right), \mathrm{I}_{5}\left(U_{2}\right), \mathrm{I}_{6}(K) ; \mathrm{H}_{2}\right]-N_{3}\left[\mathrm{I}_{4}\left(D_{1}\right), \mathrm{I}_{5}\left(U_{2}\right), \mathrm{I}_{6}(K) ; \mathrm{H}_{2}\right] \\
-N_{3}\left[\mathrm{I}_{4}\left(U_{1}\right), \mathrm{I}_{5}\left(D_{2}\right), \mathrm{I}_{6}(K) ; \mathrm{H}_{2}\right]+N_{3}\left[\mathrm{I}_{4}\left(D_{1}\right), \mathrm{I}_{5}\left(D_{2}\right), \mathrm{I}_{6}(K) ; \mathrm{H}_{2}\right] \\
-N_{3}\left[\mathrm{I}_{4}\left(U_{1}\right), \mathrm{I}_{5}\left(U_{2}\right), \mathrm{I}_{6}\left(D_{2}\right) ; \mathrm{H}_{2}\right]+N_{3}\left[\mathrm{I}_{4}\left(D_{1}\right), \mathrm{I}_{5}\left(U_{2}\right), \mathrm{I}_{6}\left(D_{2}\right) ; \mathrm{H}_{2}\right] \\
+N_{3}\left[\mathrm{I}_{4}\left(U_{1}\right), \mathrm{I}_{5}\left(D_{2}\right), \mathrm{I}_{6}\left(D_{2}\right) ; \mathrm{H}_{2}\right]-N_{3}\left[\mathrm{I}_{4}\left(D_{1}\right), \mathrm{I}_{5}\left(D_{2}\right), \mathrm{I}_{6}\left(D_{2}\right) ; \mathrm{H}_{2}\right]
\end{array}\right\}
\end{aligned}
$$


$-\sum_{n_{1}=-\infty}^{\infty} \sum_{n_{2}=-\infty}^{\infty}\left(\frac{D_{1}^{n_{1}+1}}{S_{0}^{(1)} U_{1}^{n_{1}}}\right)^{\frac{2 \mu_{1}}{\sigma_{1}^{2}}}\left(\frac{U_{2}^{n_{2}}}{D_{2}^{n_{2}}}\right)^{\frac{2 \mu_{2}}{\sigma_{2}^{2}}}$

$\left\{\begin{array}{l}N_{3}\left[\mathrm{I}_{7}\left(U_{1}\right), \mathrm{I}_{8}\left(U_{2}\right), \mathrm{I}_{9}(K) ; \mathrm{H}_{1}\right]-N_{3}\left[\mathrm{I}_{7}\left(D_{1}\right), \mathrm{I}_{8}\left(U_{2}\right), \mathrm{I}_{9}(K) ; \mathrm{H}_{1}\right] \\ -N_{3}\left[\mathrm{I}_{7}\left(U_{1}\right), \mathrm{I}_{8}\left(D_{2}\right), \mathrm{I}_{9}(K) ; \mathrm{H}_{1}\right]+N_{3}\left[\mathrm{I}_{7}\left(D_{1}\right), \mathrm{I}_{8}\left(D_{2}\right), \mathrm{I}_{9}(K) ; \mathrm{H}_{1}\right] \\ -N_{3}\left[\mathrm{I}_{7}\left(U_{1}\right), \mathrm{I}_{8}\left(U_{2}\right), \mathrm{I}_{9}\left(D_{2}\right) ; \mathrm{H}_{1}\right]+N_{3}\left[\mathrm{I}_{7}\left(D_{1}\right), \mathrm{I}_{8}\left(U_{2}\right), \mathrm{I}_{9}\left(D_{2}\right) ; \mathrm{H}_{1}\right] \\ +N_{3}\left[\mathrm{I}_{7}\left(U_{1}\right), \mathrm{I}_{8}\left(D_{2}\right), \mathrm{I}_{9}\left(D_{2}\right) ; \mathrm{H}_{1}\right]-N_{3}\left[\mathrm{I}_{7}\left(D_{1}\right), \mathrm{I}_{8}\left(D_{2}\right), \mathrm{I}_{9}\left(D_{2}\right) ; \mathrm{H}_{1}\right]\end{array}\right\}$

$+\sum_{n_{1}=-\infty}^{\infty} \sum_{n_{2}=-\infty}^{\infty}\left(\frac{D_{1}^{n_{1}+1}}{S_{0}^{(1)} U_{1}^{n_{1}}}\right)^{\left(\frac{2 \mu_{1}}{\sigma_{1}^{2}}-\frac{4 \rho \mu_{2}}{\sigma_{1} \sigma_{2}}\right)}\left(\frac{D_{2}^{n_{2}+1}}{S_{0}^{(2)} U_{2}^{n_{2}}}\right)^{\frac{2 \mu_{2}}{\sigma_{2}^{2}}}$

$\left\{\begin{array}{l}N_{3}\left[\mathrm{I}_{10}\left(U_{1}\right), \mathrm{I}_{11}\left(U_{2}\right), \mathrm{I}_{12}(K) ; \mathrm{H}_{2}\right]-N_{3}\left[\mathrm{I}_{10}\left(D_{1}\right), \mathrm{I}_{11}\left(U_{2}\right), \mathrm{I}_{12}(K) ; \mathrm{H}_{2}\right] \\ -N_{3}\left[\mathrm{I}_{10}\left(U_{1}\right), \mathrm{I}_{11}\left(D_{2}\right), \mathrm{I}_{12}(K) ; \mathrm{H}_{2}\right]+N_{3}\left[\mathrm{I}_{10}\left(D_{1}\right), \mathrm{I}_{11}\left(D_{2}\right), \mathrm{I}_{12}(K) ; \mathrm{H}_{2}\right] \\ -N_{3}\left[\mathrm{I}_{10}\left(U_{1}\right), \mathrm{I}_{11}\left(U_{2}\right), \mathrm{I}_{12}\left(D_{2}\right) ; \mathrm{H}_{2}\right]+N_{3}\left[\mathrm{I}_{10}\left(D_{1}\right), \mathrm{I}_{11}\left(U_{2}\right), \mathrm{I}_{3}\left(D_{2}\right) ; \mathrm{H}_{2}\right] \\ +N_{3}\left[\mathrm{I}_{10}\left(U_{1}\right), \mathrm{I}_{11}\left(D_{2}\right), \mathrm{I}_{12}\left(D_{2}\right) ; \mathrm{H}_{2}\right]-N_{3}\left[\mathrm{I}_{10}\left(D_{1}\right), \mathrm{I}_{11}\left(D_{2}\right), \mathrm{I}_{12}\left(D_{2}\right) ; \mathrm{H}_{2}\right]\end{array}\right\}$

where $N_{3}[., ., ., \ldots, .,$.$] is the trivariate standard normal cumulative distribution as defined in$ Proposition 2, and where the remaining functions are given by:

$$
\begin{aligned}
& \mathrm{I}_{1}(X)=\left(\ln \left(\frac{X D_{1}^{2 n_{1}}}{S_{0}^{(1)} U_{1}^{2 n_{1}}}\right)-\mu_{1} t_{1}\right) / \sigma_{1} \sqrt{t_{1}}, \mathrm{I}_{2}(X)=\left(\ln \left(\frac{X}{S_{0}^{(2)}}\right)-\mu_{2} t_{1}\right) / \sigma_{2} \sqrt{t_{1}}+\ln \left(\frac{D_{1}^{2 \rho n_{1}}}{U_{1}^{2 \rho n_{1}}}\right) / \sigma_{1} \sqrt{t_{1}} \\
& \mathrm{I}_{3}(X)=\left(\ln \left(\frac{X D_{2}^{2 n_{2}}}{S_{0}^{(2)} U_{2}^{2 n_{2}}}\right)-\mu_{2} t_{2}\right) / \sigma_{2} \sqrt{t_{2}}+\ln \left(\frac{D_{1}^{2 \rho n_{1}}}{U_{1}^{2 \rho n_{1}}}\right) / \sigma_{1} \sqrt{t_{2}} \\
& \mathrm{I}_{4}(X)=\mathrm{I}_{1}(x)-\frac{2 \rho \mu_{2} \sqrt{t_{1}}}{\sigma_{2}}, \mathrm{I}_{5}(X)=\left(\ln \left(\frac{X}{S_{0}^{(2)}}\right)+\mu_{2} t_{1}\right) / \sigma_{2} \sqrt{t_{1}}+\ln \left(\frac{D_{1}^{2 \rho n_{1}}}{U_{1}^{2 \rho n_{1}}}\right) / \sigma_{1} \sqrt{t_{1}} \\
& \mathrm{I}_{6}(X)=\left(\ln \left(\frac{X S_{0}^{(2)} U_{2}^{2 n_{2}}}{D_{2}^{2\left(n_{2}+1\right)}}\right)-\mu_{2} t_{2}\right) / \sigma_{2} \sqrt{t_{2}}+\ln \left(\frac{U_{1}^{2 \rho n_{1}}}{D_{1}^{2 \rho n_{1}}}\right) / \sigma_{1} \sqrt{t_{2}} \\
& \mathrm{I}_{7}(X)=\left(\ln \left(\frac{X S_{0}^{(1)} U_{1}^{2 n_{1}}}{D_{1}^{2\left(n_{1}+1\right)}}\right)-\mu_{1} t_{1}\right) / \sigma_{1} \sqrt{t_{1}}, \\
& \mathrm{I}_{8}(X)=\left(\ln \left(\frac{X}{S_{0}^{(2)}}\right)-\mu_{2} t_{1}\right) / \sigma_{2} \sqrt{t_{1}}+\ln \left(\frac{\left(S_{0}^{(1)}\right)^{2 \rho} U_{1}^{2 \rho n_{1}}}{D_{1}^{2 \rho\left(n_{1}+1\right)}}\right) / \sigma_{1} \sqrt{t_{1}} \\
& \mathrm{I}_{9}(X)=\left(\ln \left(\frac{X D_{2}^{2 n_{2}}}{S_{0}^{(2)} U_{2}^{2 n_{2}}}\right)-\mu_{2} t_{2}\right) / \sigma_{2} \sqrt{t_{2}}+\ln \left(\frac{\left(S_{0}^{(1)}\right)^{2 \rho} U_{1}^{2 \rho n_{1}}}{D_{1}^{2 \rho\left(n_{1}+1\right)}}\right) / \sigma_{1} \sqrt{t_{2}} \\
& \mathrm{I}_{10}(x)=\mathrm{I}_{7}(x)-\frac{2 \rho \mu_{2} \sqrt{t_{1}}}{\sigma_{2}}, \\
& \mathrm{I}_{11}(X)=\left(\ln \left(\frac{X}{S_{0}^{(2)}}\right)+\mu_{2} t_{1}\right) / \sigma_{2} \sqrt{t_{1}}+\ln \left(\frac{\left(S_{0}^{(1)}\right)^{2 \rho} U_{1}^{2 \rho n_{1}}}{D_{1}^{2 \rho\left(n_{1}+1\right)}}\right) / \sigma_{1} \sqrt{t_{1}} \\
& \left.\ln \left(\frac{X S_{0}^{(2)} U_{2}^{2 n_{2}}}{D_{2}^{2\left(n_{2}+1\right)}}\right)-\mu_{2} t_{2}\right) / \sigma_{2} \sqrt{t_{2}}+\ln \left(\frac{D_{1}^{2 \rho\left(n_{1}+1\right)}}{\left(S_{0}^{(1)}\right)^{2 \rho} U_{1}^{2 \rho n_{1}}}\right) / \sigma_{1} \sqrt{t_{2}} \\
&
\end{aligned}
$$




$$
\mathrm{H}_{1}=\left\{\rho, \rho \sqrt{\frac{t_{1}}{t_{2}}}, \sqrt{\frac{t_{1}}{t_{2}}}\right\}, \mathrm{H}_{2}=\left\{\rho,-\rho \sqrt{\frac{t_{1}}{t_{2}}},-\sqrt{\frac{t_{1}}{t_{2}}}\right\}
$$

The numerical implementation of Proposition 7 is identical to that of Proposition 2.

The value of a two-asset two-step double knock-out call, TATSDKOC, is obtained as follows :

$$
\begin{aligned}
& \operatorname{TATSDKOC}\left(S_{0}^{(1)}, S_{0}^{(2)}, \sigma_{1}, \sigma_{2}, r, \delta_{1}, \delta_{2}, t_{1}, t_{2}, K, U_{1}, U_{2}, D_{1}, D_{2}\right) \\
& =\operatorname{TATSDKOP}\left(S_{0}^{(1)}, S_{0}^{(2)}, \sigma_{1}, \sigma_{2}, r, \delta_{1}, \delta_{2}, t_{1}, t_{2}, U_{2}, U_{1}, U_{2}, D_{1}, D_{2}\right) \\
& -\operatorname{TATSDKOP}\left(S_{0}^{(1)}, S_{0}^{(2)}, \sigma_{1}, \sigma_{2}, r, \delta_{1}, \delta_{2}, t_{1}, t_{2}, K, U_{1}, U_{2}, D_{1}, D_{2}\right)
\end{aligned}
$$

\section{APPENDIX 2}

The Markovian property of the underlying asset price processes as well as the knowledge of closed form formulae for two-step double barrier options can both be exploited to devise a very efficient and accurate conditional Monte Carlo scheme enhanced with control variates to value step double barrier options with any number of steps.

Denote by $n$ the number of steps in your option. The conditional Monte Carlo method, relying on a process known as Brownian bridge (El Babsiri and Noel [1998], Glasserman [2004]), can be fruitfully applied to our valuation problem to allow us to simulate only the values of the underlying asset $S$ at the dates $t_{i}, i \in\{1, \ldots, n\}$, at which the double barrier changes, without having to simulate all the intermediary values inside each time interval $\left[t_{i-1}, t_{i}\right]$, which dramatically curtails the usual computational burden involved with the Monte Carlo simulation of a path-dependent option. If the condition tested at expiry is met, the option payoff associated with each simulation needs only be multiplied by the product of the conditional probabilities that the underlying asset price has stayed within the specified range in every $\left[t_{i-1}, t_{i}\right]$ knowing each $S\left(t_{i}\right)$. The latter are provided by the following lemma.

Lemma Let $\{S(t), t \geq 0\}$ be a process defined on a suitable probability space $\left(\Omega, F, \mathcal{F}_{t}, \mathbb{P}\right)$ by the following stochastic differential equation : $d S(t)=\mu S(t) d t+\sigma S(t) d B(t)$, where $\mu$ is a real constant and $\sigma$ is a positive constant and $\{B(t), t \geq 0\}$ is a standard Brownian motion. Let $D$ and $U$ be two real numbers such that $D<S_{0}<U$. Then,

$$
\begin{aligned}
& \mathbb{P}\left(\sup _{t_{i} \leq t \leq t_{j}} S_{t}<U, \inf _{t_{i} \leq t \leq t_{j}} S_{t}>D \mid S_{t_{i}}, S_{t_{j}}\right), \quad t_{0}=0<t_{i}<t_{j} \\
& =\sum_{n=-\infty}^{\infty}\left(\frac{S_{t_{j}} D^{n}}{S_{t_{i}} U^{n}}\right)^{\frac{\ln \left(\frac{U^{2 n}}{D^{2 n}}\right)}{\sigma^{2}\left(t_{j}-t_{i}\right)}}-\sum_{n=-\infty}^{\infty}\left(\frac{S_{t_{j}} U^{n-1}}{D^{n}}\right)^{\left.\frac{U^{2(1-n)} D^{2 n}}{S_{t_{i}}^{2}}\right)}
\end{aligned}
$$


Moreover, the closed form formula for a two-step double barrier option given in Proposition 1 of Appendix 1 can be used to further improve the previous scheme with the help of a control variate. Pick one of the dates $t_{i}, i \in\{1, \ldots, n\}$, in your $n$-step barrier option, and denote it as $t_{i}{ }^{*}$. The optimal $t_{i}^{*}$, i.e. the one that minimizes the variance of your Monte Carlo estimator, may vary according to the specifics of the option contract, but, to make matters simple, say you choose $t_{i} *$ close to half the option lifetime. Then, define a two-step double barrier as follows : $\bar{U}_{1}=\sum_{i=1}^{i^{*}} U_{i} \frac{\left(t_{i}-t_{i-1}\right)}{t_{i^{*}}}$, $\bar{D}_{1}=\sum_{i=1}^{i^{*}} D_{i} \frac{\left(t_{i}-t_{i-1}\right)}{t_{i^{*}}}, \bar{U}_{2}=\sum_{i=i^{*}+1}^{n} U_{i} \frac{\left(t_{i}-t_{i-1}\right)}{t_{n}-t_{i^{*}}}, \bar{D}_{2}=\sum_{i=i^{*}+1}^{n} D_{i} \frac{\left(t_{i}-t_{i-1}\right)}{t_{n}-t_{i^{*}}}$, where all the $U_{i}{ }^{\prime} \mathrm{s}$ and $D_{i}{ }^{\prime}$ s are specified in the $n$-step double barrier option contract. In other words, $\bar{U}_{1}, \bar{D}_{1}, \bar{U}_{2}$ and $\bar{D}_{2}$ are defined as averages of the the $U_{i}$ 's and $D_{i}{ }^{\prime}$ s weighted by the time span during which they are monitored. You can now use this newly created two-step double barrier option, which you can price in closed form with Proposition 1 of Appendix 1, as a control variate for your simulation. The combination of this control variate with the previous conditional Monte Carlo scheme leads to a spectacular variance reduction compared with a standard Monte Carlo simulation, making it possible to achieve very good pricing accuracy with a small number of simulations. We now provide a detailed algorithm for implementation. It is supposed that the option to be valued is an $n$-step knock-out double barrier call. The algorithm easily carries over to other types of $n$-step double barrier option payoffs.

\section{Algorithm for the valuation of an $n$-step knock-out double barrier call}

We want to estimate $\mathbb{E}[X]$, under the risk-neutral measure, where $X$ is the payoff of an $n$-step knock-out double barrier call. We will use $Y$ as a control variate, where $Y$ is the payoff of a two-step knock-out double barrier call as defined at the beginning of Appendix 2; $\mathbb{E}[Y]$ can be known exactly by means of Proposition 1 in Appendix 1.

Our control variate conditional Monte Carlo estimator, denoted by $\hat{\mathbb{E}}_{C V C M C}[X]$, will be given by :

$$
\hat{\mathbb{E}}_{C V C M C}[X]=\hat{\mathbb{E}}_{C M C}[X]+c\left(\hat{\mathbb{E}}_{C M C}[Y]-\mathbb{E}[Y]\right)
$$

where $\hat{\mathbb{E}}_{C M C}$ [.] stands for a conditional Monte Carlo estimator. According to the theory of control variates, the constant $c$ has to be determined so that the variance of the estimator is minimized (Glasserman [2004]). This easily yields : $c=\frac{-\operatorname{cov}[X, Y]}{\operatorname{var}[Y]}$. 


\section{Stage 1}

For $j=1, \ldots, N_{1}$, simulate a pilot of $N_{1}$ independent vectors $\left[S_{t_{1}}^{(j)}, S_{t_{2}}^{(j)}, \ldots, S_{t_{n}}^{(j)}\right]$ to obtain $N_{1}$ payoffs of $n$-step knock-out double barrier call options and $N_{1}$ payoffs of two-step knock-out double barrier call options. It can be recommended to choose a reasonably low value for $N_{1}$, such as $N_{1}=5000$, because stage 1 of the algorithm needs to be carried out quickly for the control variate technique to have a positive net effect on the efficiency of the Monte Carlo simulation, and because the resulting loss of accuracy in the estimation of the constant $c$ is not very significant.

Each $n$-step knock-out double barrier call payoff associated with simulation $j$, denoted by $X^{(j)}$, writes as follows :

$$
X^{(j)}=\left(S_{t_{n}}^{(j)}-K\right) \mathbb{I}\left\{S_{t_{n}}^{(j)}>K\right\} \prod_{i=1}^{n}\left\{\sum_{m=-\infty}^{\infty}\left(\frac{S_{t_{i}}^{(j)} D_{i}^{m}}{S_{t_{i-1}}^{(j)} U_{i}^{m}}\right)^{\frac{\ln \left(\frac{U_{i}^{2 m}}{D_{i}^{2 m}}\right)}{\sigma^{2}\left(t_{i}-t_{i-1}\right)}}-\sum_{m=-\infty}^{\infty}\left(\frac{S_{t_{i}}^{(j)} U_{i}^{m-1}}{D_{i}^{m}}\right)^{\frac{\ln \left(\frac{U_{i}^{2(1-m)} D_{i}^{2 m}}{\left(S_{t_{i}}^{(j)}\right.}\right)}{\sigma^{2}\left(t_{i}-t_{i-1}\right)}}\right\}
$$

Of course, the infinite sum will be truncated. Along the lines of Schroder [1998], it can be shown that this sum rapidly converges, so that it can be truncated to $m=-5 \ldots 5$ without loss of precision for all practical purposes.

Similarly, each two-step knock-out double barrier call payoff associated with simulation $j$, denoted by $Y^{(j)}$, writes as follows :

$$
\begin{aligned}
& Y^{(j)}=\left(S_{t_{n}}^{(j)}-K\right) \mathbb{I}\left\{S_{t_{n}}^{(j)}>K\right\}\left(\sum_{m=-\infty}^{\infty}\left(\frac{S_{t_{i^{*}}}^{(j)} \bar{D}_{1}^{m}}{S_{t_{0}} \bar{U}_{1}^{m}}\right)^{\frac{\ln \left(\frac{\bar{U}_{1}^{2 m}}{\bar{D}_{1}^{2 m}}\right)}{\sigma_{i^{*}}}}-\sum_{m=-\infty}^{\infty}\left(\frac{S_{t_{i}{ }^{*}}^{(j)} \bar{U}_{1}^{m-1}}{\bar{D}_{1}^{m}}\right)^{\left.\frac{\ln \left(\frac{\bar{U}_{1}^{2(1-m)} \bar{D}_{1}^{2 m}}{\left(S_{t^{*}}^{(j)}\right)^{2}}\right)}{\sigma^{2} t_{i^{*}}}\right)}\right) \\
& \left(\sum_{m=-\infty}^{\infty}\left(\frac{S_{t_{n}}^{(j)} \bar{D}_{2}^{m}}{S_{t_{i^{*}}}^{(j)} \bar{U}_{2}^{m}}\right)^{\frac{\ln \left(\frac{\bar{U}_{2}^{2 m}}{\bar{D}_{2}^{2 m}}\right)}{\sigma^{2}\left(t_{n}-t_{i^{*}}\right)}}-\sum_{m=-\infty}^{\infty}\left(\frac{S_{t_{n}}^{(j)} \bar{U}_{2}^{m-1}}{\bar{D}_{2}^{m}}\right)^{\frac{\ln \left(\frac{\bar{U}_{2}^{2(1-m)} \bar{D}_{2}^{2 m}}{\left(S_{t_{n}}^{(j)}\right)^{2}}\right)}{\sigma^{2}\left(t_{n}-t_{i^{*}}\right)}}\right)
\end{aligned}
$$




\section{Stage 2}

The quantity $\operatorname{var}[Y]$ is now estimated by : $\frac{1}{N_{1}-1} \sum_{j=1}^{N_{1}}\left(Y^{(j)}-\hat{\mathbb{E}}_{C M C}[Y]\right)^{2}$, where $\hat{\mathbb{E}}_{C M C}[Y]=\frac{1}{N_{1}} \sum_{j=1}^{N_{1}} Y^{(j)}$, and the quantity $\operatorname{cov}[X, Y]$ is estimated by :

$\operatorname{cov}[X, Y]=\frac{1}{N_{1}-1} \sum_{j=1}^{N_{1}}\left(Y^{(j)}-\hat{\mathbb{E}}_{C M C}[Y]\right)\left(X^{(j)}-\hat{\mathbb{E}}_{C M C}[X]\right)$

\section{Stage 3}

Conditional Monte Carlo simulations of $X^{(h)}$ and $Y^{(h)}$ are now performed for $h=1, \ldots, N_{2}$ realizations of independent vectors $\left[S_{t_{1}}^{(h)}, S_{t_{2}}^{(h)}, \ldots, S_{t_{n}}^{(h)}\right]$, using eq. (24) and (25) given at stage 1 of the algorithm. The resulting estimator of the $n$-step knock-out double barrier call value obtained after $N_{2}$ simulations is provided by :

$\hat{\mathbb{E}}_{C V C M C}[X]=$

$\frac{1}{N_{2}} \sum_{h=1}^{N_{2}} X^{(h)}-\frac{\frac{1}{N_{1}-1} \sum_{j=1}^{N_{1}}\left(Y^{(j)}-\frac{1}{N_{1}} \sum_{j=1}^{N_{1}} Y^{(j)}\right)\left(X^{(j)}-\frac{1}{N_{1}} \sum_{j=1}^{N_{1}} X^{(j)}\right)}{\frac{1}{N_{1}-1} \sum_{j=1}^{N_{1}}\left(Y^{(j)}-\frac{1}{N_{1}} \sum_{j=1}^{N_{1}} Y^{(j)}\right)^{2}}\left(\frac{1}{N_{2}} \sum_{h=1}^{N_{2}} Y^{(h)}-\mathbb{E}[Y]\right)$

where $\mathbb{E}[Y]$ is computed with Proposition 1 in Appendix 1.

By evaluating the standard error of the estimator, it is possible to measure the variance reduction achieved by the previous algorithm with respect to a standard Monte Carlo simulation. Out of a random sample of 1000 different contract specifications of a 16-step knock-out double barrier call, we found an average variance reduction of $92.3 \%$. To achieve the same level of standard error with a standard Monte Carlo simulation, the number of simulations required would have to be multiplied by close to a hundred. Given that standard Monte Carlo is much slower due to the necessary simulation of the entire asset price path, computational time would then explode and become unacceptable in trading time. 


\section{REFERENCES}

El Babsiri, M., G. Noel, "Simulating Path-Dependent Options : A New Approach", Journal of Derivatives, Vol. 6, No.2 (1998), 65-83

Geman, H., M. Yor, "Pricing and hedging double-barrier options : a probabilistic approach", Mathematical Finance, 6 (1996), 365-378

Genz, A., "Numerical Computation of Rectangular Bivariate and Trivariate Normal and t Probabilities", Statistics and Computing, 14 (2004), 151-160

Glasserman, P., Monte Carlo Methods in Financial Engineering, Springer-Verlag, 2004

Guillaume, T., "Window double barrier options", Review of Derivatives Research, 6 (2003), 47-75

Hui, C. H., "Time-dependent barrier option values", The Journal of Futures Markets, 17 (1997), $667-$ 688

Kunitomo, N., M., Ikeda, "Pricing options with curved boundaries", Mathematical Finance, 2 (1992), 275-298

Lin, X.S., "Double barrier hitting time distributions with applications to exotic options, Insurance : Mathematics and Economics", 23 (1998), 45-58

Luo, L. S.J., "Various types of double-barrier options", Journal of Computational Finance, 4 (3) (2007), 125-137

Pelsser, A., "Pricing double barrier options using Laplace transforms", Finance and Stochastics, 4 (2000), 95-104

Schröder, M., "On the valuation of double-barrier options : computational aspects", Journal of Computational Finance, 3 (4) (2000), 5-33

Sepp, A., "Analytical pricing of double-barrier options under a double-exponential jump diffusion process : applications of Laplace transform", International Journal of Theoretical and Applied Finance, 7 (2004), 151-175

Wystup, U., FX Options and Structured Products, John Wiley \& Sons, 2006 


\section{EXHIBIT 1}

Double knock-out put values

\begin{tabular}{|l|l|l|l|}
\hline & volatility $=15 \%$ & volatility $=30 \%$ & volatility = 45\% \\
\hline $\mathrm{K}=90$ & 0.62772464 & 1.61554066 & 0.93264185 \\
\hline $\mathrm{K}=100$ & 3.47861265 & 4.74129577 & 2.6156452 \\
\hline $\mathrm{K}=110$ & 9.76902226 & 9.58790455 & 5.0999067 \\
\hline
\end{tabular}

Note. This table reports the values of double knock-out put options for various levels of strike and volatility. All prices are computed by means of Proposition 1 in Appendix 1 with the following parameters :

$\mathrm{S}(0)=100$, expiry=0.5, $\mathrm{D}=70, \mathrm{U}=130, \mathrm{r}=3 \%, \delta=0$ 
EXHIBIT 2

Two-step double knock-out put values

\begin{tabular}{|l|l|l|l|}
\hline & volatility = 15\% & volatility = 30\% & volatility = 45\% \\
\hline $\mathrm{K}=90$ & 0.56253297 & 0.82180602 & 0.35848887 \\
\hline $\mathrm{K}=100$ & 3.36751191 & 3.19407995 & 1.36185154 \\
\hline $\mathrm{K}=110$ & 9.61103335 & 7.18690531 & 3.00322414 \\
\hline
\end{tabular}

Note. This table reports the values of two-step double knock-out put options for various levels of strike and volatility. All prices are computed by means of Proposition 1 in Appendix 1 with the following parameters : $\mathrm{S}(0)=100, \mathrm{t}_{1}=0.25, \mathrm{t}_{2}=0.5, \mathrm{D}_{1}=70, \mathrm{U}_{1}=130, \mathrm{D}_{2}=75, \mathrm{U}_{2}=125, \mathrm{r}=3 \%, \delta=0$ 
EXHIBIT 3

Illustration of the numerical results presented in Exhibit 1 and Exhibit 2

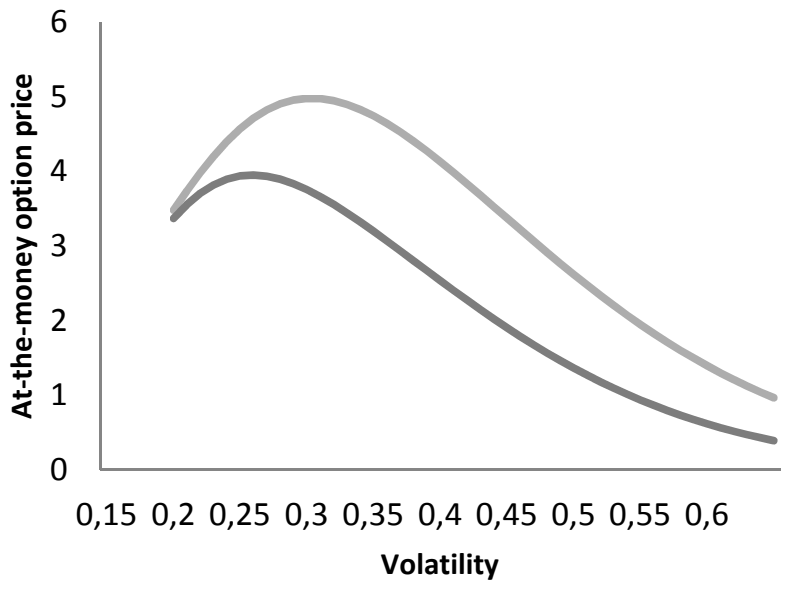

Double knock-out

Two-step double knock-out 
EXHIBIT 4

Risk-neutral probabilities of knocking-out before expiry

\begin{tabular}{|l|l|l|l|}
\hline & volatility $=15 \%$ & volatility $=30 \%$ & volatility $=45 \%$ \\
\hline $\begin{array}{l}\mathrm{D}=70, \mathrm{U}=130 \\
\text { expiry }=0.5\end{array}$ & 0.01716411 & 0.30512157 & 0.66049856 \\
\hline $\begin{array}{l}\mathrm{D}_{1}=70, \mathrm{U}_{1}=130 \\
\mathrm{D}_{2}=60, \mathrm{U}_{2}=140 \\
\mathrm{t}_{1}=0.25, \mathrm{t}_{2}=0.5\end{array}$ & 0.00236331 & 0.16247899 & 0.49117472 \\
\hline $\begin{array}{l}\mathrm{D}=70, \mathrm{U}=130 \\
\text { expiry=1 }\end{array}$ & 0.11219931 & 0.60932096 & 0.90835961 \\
\hline $\begin{array}{l}\mathrm{D}_{1}=70, \mathrm{U}_{1}=130 \\
\mathrm{D}_{2}=60, \mathrm{U}_{2}=140\end{array}$ & 0.04107022 & 0.43900563 & 0.81107432 \\
$\mathrm{t}_{1}=0.5, \mathrm{t}_{2}=1$ & & & \\
\hline
\end{tabular}

Note. This table reports risk-neutral probabilities of knocking-out before expiry associated with constant and two-step double barriers with six-month and one-year expiries. These probabilities are obtained by using Proposition 1 in Appendix 1 with a risk-neutral drift, a strike price equal to the level of the upper barrier, and the following parameters : $\mathrm{S}(0)=100, \mathrm{r}=3 \%, \delta=0$. 


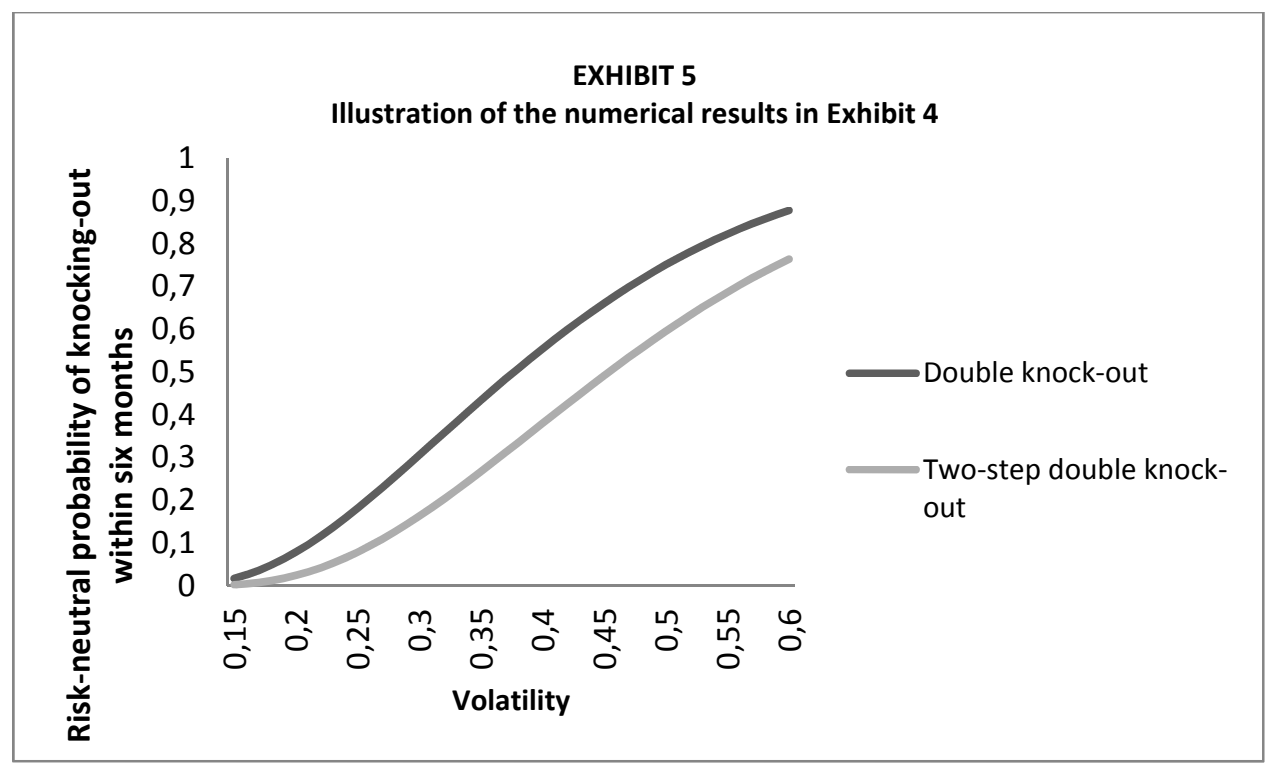




\section{EXHIBIT 6}

Realised yields on long option positions

\begin{tabular}{|l|l|l|l|}
\hline & $\mathrm{S}\left(\mathrm{t}_{3}\right)=105$ & $\mathrm{~S}\left(\mathrm{t}_{3}\right)=110$ & $\mathrm{~S}\left(\mathrm{t}_{3}\right)=120$ \\
\hline vanilla call & $-62.36 \%$ & $-24.72 \%$ & $50.56 \%$ \\
\hline $\begin{array}{l}\text { double knock-in call } \\
\mathrm{U}=130, \mathrm{D}=70, \text { expiry }=1\end{array}$ & $-59.4 \%$ & $-18.81 \%$ & $62.38 \%$ \\
\hline $\begin{array}{l}\text { two-step double knock-in call } \\
\mathrm{U}_{1}=130, \mathrm{D}_{1}=70, \mathrm{U}_{2}=135, \mathrm{D}_{2}=65\end{array}$ & $-55.56 \%$ & $-11.11 \%$ & $77.77 \%$ \\
$\mathrm{t}_{1}=0.5, \mathrm{t}_{2}=$ expiry $=1$ & & & \\
\hline $\begin{array}{l}\text { early ending two-step double knock-in call number } 1 \\
\mathrm{U}_{1}=130, \mathrm{D}_{1}=70, \mathrm{U}_{2}=125, \mathrm{D}_{2}=75\end{array}$ & $-45.78 \%$ & $8.44 \%$ & $116.88 \%$ \\
$\mathrm{t}_{1}=0.25, \mathrm{t}_{2}=0.5, \mathrm{t}_{3}=$ expiry=1 & & & \\
\hline $\begin{array}{l}\text { early ending two-step double knock-in call number } 2 \\
\mathrm{U}_{1}=130, \mathrm{D}_{1}=70, \mathrm{U}_{2}=135, \mathrm{D}_{2}=65\end{array}$ & $-29.7 \%$ & $40.6 \%$ & $181.21 \%$ \\
$\mathrm{t}_{1}=0.25, \mathrm{t}_{2}=0.5, \mathrm{t}_{3}=$ expiry=1 & & & \\
\hline
\end{tabular}

Note. This table compares realised yields on several long option positions for three possible values of the underlying asset $\mathrm{S}$ at expiry $\mathrm{t}_{3}$, under the assumption that the knock-in options have been activated. The implied option prices are computed by means of Proposition 1 and Proposition 2 in Appendix 1 with the following parameters : $\mathrm{S}(0)=100, \mathrm{~K}=100, \sigma=30 \%, \mathrm{r}=3 \%, \delta=0$ 


\section{EXHIBIT 7}

Prices of various out-of-the-money six-month expiry call options

\begin{tabular}{|l|l|l|}
\hline & volatility $=15 \%$ & volatility $=30 \%$ \\
\hline $\begin{array}{l}\text { vanilla call } \\
\text { expiry }=0.5\end{array}$ & 0.2823 & 2.82 \\
\hline two-step double knock-out call & 0.1086 & 0.092 \\
$\mathrm{U}_{1}=125, \mathrm{D}_{1}=75, \mathrm{U}_{2}=130, \mathrm{D}_{2}=70$ & & \\
$\mathrm{t}_{1}=0.25, \mathrm{t}_{2}=$ expiry $=0.5$ & & \\
\hline early-ending two-step double knock-out call & 0.2755 & 1.6165 \\
$\mathrm{U}_{1}=125, \mathrm{D}_{1}=75, \mathrm{U}_{2}=130, \mathrm{D}_{2}=70$ & & \\
$\mathrm{t}_{1}=0.125, \mathrm{t}_{2}=0.25, \mathrm{t}_{3}=$ expiry $=0.5$ & & \\
\hline
\end{tabular}

Note. This table reports the values of three different out-of-the-money six-month expiry call options for two levels of volatility of the underlying asset. All prices are obtained by means of Proposition 1 and Proposition 2 of Appendix 1 with the following parameters : $\mathrm{S}(0)=100, \mathrm{~K}=120, \mathrm{r}=3 \%, \delta=0$ 


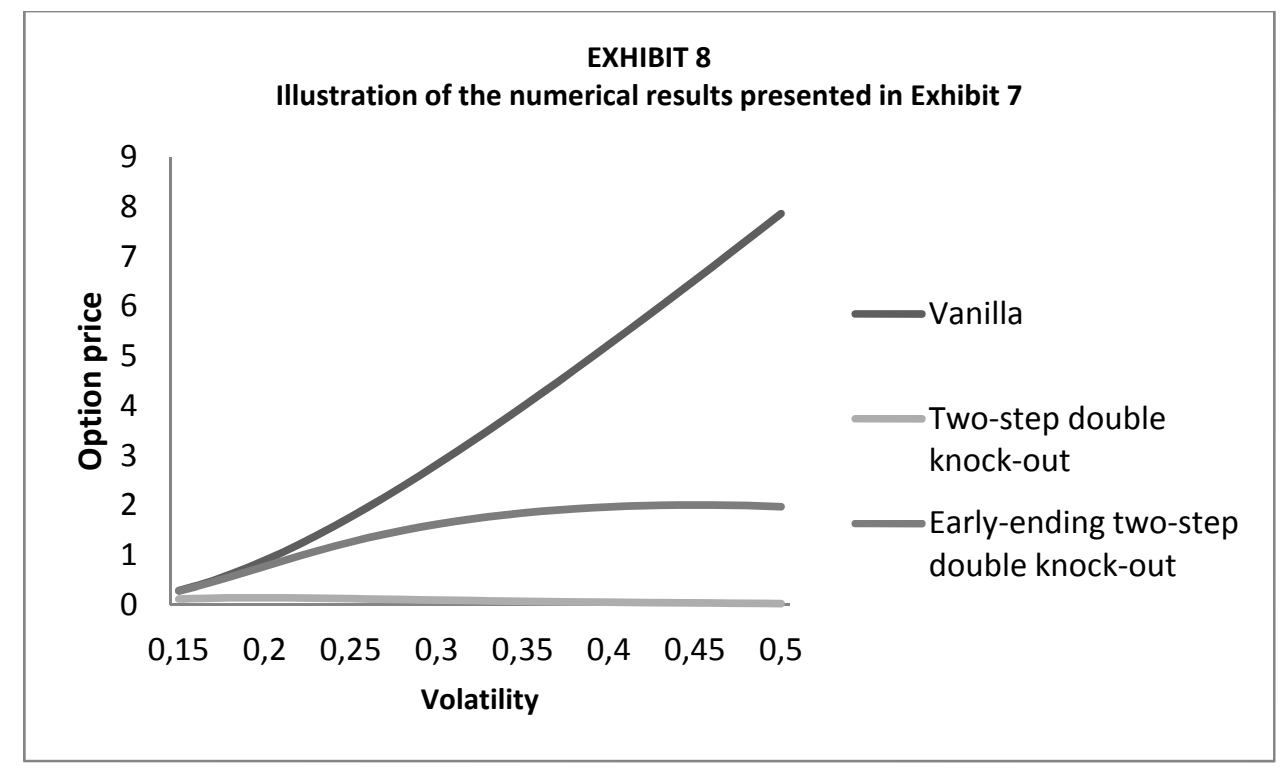

